\title{
Numerical modeling on compressive behaviors of 3-D braided composites under high temperatures at microstructure level
}

\author{
Hailou Wang, Baozhong Sun, Bohong Gu* \\ (*: Email: gubh@dhu.edu.cn Tel: +86-21-67792661, Fax: +86-21-67792627) \\ College of Textiles, Donghua University, Shanghai, China, 201620
}

\begin{abstract}
This paper reports a numerical modeling on the compressive behaviors of 3-D braided carbon / epoxy composites with different braided angles under high temperatures at microstructure level. The coupling effect of temperature and braided angle on the compressive failure mechanisms and damage morphologies have been calculated with finite element method (FEM) and compared with experimental results. In the FEM model, the imperfect interfacial bonding and the fibers with waviness were introduced into the FEM model. The ductile/brittle transition temperature was investigated and the ductile failure criterion was employed in the FEM model at high temperatures. It was found that braided angle affects the compressive failure. The compressive failure changes from ductile to brittle when the braided angle changes from larger to smaller one. The high temperature has almost no influence on the damage mode but it leads to the failure modes more ductile. The thermal stress improves the longitudinal compressive properties. The higher temperature and larger braided angle lead to the ductile behaviors of the 3D braided under longitudinal compression.
\end{abstract}

Keywords: 3D braided composite; high temperature; ductile/brittle transition; failure mechanism; finite element method (FEM). 


\section{Introduction}

Braided composites are often used in high temperature applications and there is very limited literature on mechanical behaviors of 3D braided composite. The study of mechanical behaviors of the 3D braided composites under high temperatures is very important in practical and in theoretical applications.

The influences of temperature on compressive behaviors of 3D braided composites have been investigated at high and low temperature in experimental [1-5]. In numerical, representative volume cell (RVC) method [6, 7], multi-unit cell model (MUCM) [8-10] and multi-scale structure model [11] were often employed to predict mechanical behaviors of 3D braided composites. However, the damage morphologies and failure mechanisms cannot be revealed from the three kinds of geometrical models because the geometrical structures of braided preform and resin were homogenized into a RVCs or unit cells.

Here we report a full-scale microstructure model of 3D braided composites for the investigation of the compressive damage under high temperature environment. The influence of temperatures and the braided angles on the compressive behaviors will be studied from experimental and finite element analyses (FEA) approach. The coupling effect of the thermo-mechanical effect was introduced in the FEA model. The compressive behaviors and damage morphologies will be presented from the experimental results and numerical simulations. We hope the comparisons between the experimental and numerical will verify the FEA model and furthermore will find the compressive failure mechanisms from the microstructure level.

\section{Materials and tests}

Three-dimensional (3D) braided carbon fiber tows (T700-12k) preform was prepared with 4 -step $1 \times 1$ braided method in yarn array of $10 \times 10$ as shown in Fig. 1(a). Epoxy resin was injected into the 3D braided preform with vacuum assisted resin transfer molding (VARTM) technique as shown in Fib. 1(b). The resin is composed of epoxy resin (JC-02A) and hardener (JC-02B) with a weight ratio of 10:8. Fig. 1(c) presents the cured samples. Table 1 lists the coupon specifications. 
Fig. 2 shows a self-designed high-temperature chamber. TC1 and TC2 are thermocouples used to monitor temperature. TC1 detects the internal temperature of the reference specimen and TC2 detects the environment temperature. The compression tests were conducted on an MTS810 servo-hydraulic materials tester. All the specimens were compressed at a velocity of $2 \mathrm{~mm} / \mathrm{min}$. The test was repeated three times at each condition.

\section{Full-scale microstructure model}

\subsection{Modeling approach}

Braided composites consist of yarn and resin matrix. The yarn, which is used as reinforcement in the braided composites, is composed of fiber and resin. Usually, the interface between fiber and resin is assumed perfect and the fibers inside the yarn are aligned perfectly but in reality, the interfaces are not perfectly bonded which influence the mechanical properties of composites. Here the imperfect interfacial bonding and the fibers with waviness were introduced into the full-scale microstructure model. Fig. 3 shows the framework of the FEM model for 3D braided composites.

\subsection{Geometry model}

The geometry model of braided preform is established based on the real structure as shown in Fig. 4. This model ensures that the adjacent faces among yarns are parallel due to the compaction among yarns and the surface of the braided preform is flat because of the pressure of mould during the composite consolidation. The cross section shape of the braiding yarns is assumed to be hexagon as shown in Fig. 4(b). The matrix is cut from the geometric model of the braided preform. The related geometric parameters for the hexagon section are derived as follows:

$$
\begin{aligned}
& Y_{a}=V(y) \times \frac{\sqrt{1+\cot ^{2} \alpha}}{4 \sqrt{2+\cot ^{2} \alpha}} \mathrm{W} \\
& Y_{\mathrm{w}}=\mathrm{V}(\mathrm{y}) \times \frac{\sqrt{2}}{4} \mathrm{~W} \\
& \mathrm{Y}_{\mathrm{d}}=2 \mathrm{Y}_{\mathrm{a}}
\end{aligned}
$$

where $\mathrm{V}(\mathrm{y})$ is a coefficient related to the yarn volume fraction; $\mathrm{W}$ is the repeating unit 
width; $a$ is the braided angle. In this article, the value of $\mathrm{V}(\mathrm{y})$ is 0.7 .

\subsection{Material model}

It is assumed that the braided yarns are transversely isotropic unidirectional composites and the resin is isotropic material. A unique local coordinate system for each yarn is defined corresponding to the yarn axial direction because of the variation of the yarn space trajectory.

The carbon fiber is assumed as a linear elastic material. The resin is assumed to be a elastic-plastic solid based on a Von Mises yield criterion [12]. The braided yarn is constructed as an elastic-plastic material obeying the Hill's potential function [13].

Hill's potential function is an extension of the Von Mises function.

$$
f(\sigma)=\sqrt{\mathrm{F}\left(\sigma_{22}-\sigma_{33}\right)^{2}+\mathrm{G}\left(\sigma_{33}-\sigma_{11}\right)^{2}+\mathrm{H}\left(\sigma_{11}-\sigma_{22}\right)^{2}+2 \mathrm{~L} \sigma_{23}^{2}+2 \mathrm{M} \sigma_{31}^{2}+2 \mathrm{~N} \sigma_{12}^{2}}
$$

For the yarns, which are orthotropic materials, the Hill's potential function is simplified into [14]:

$$
\begin{aligned}
& f(\sigma)=\sqrt{\mathrm{F}\left(\sigma_{22}-\sigma_{33}\right)^{2}+2 \mathrm{~L} \sigma_{23}^{2}+2 \mathrm{M}\left(\sigma_{31}^{2}+\sigma_{12}^{2}\right)} \\
& \mathrm{F}=\frac{\left(\sigma_{0}\right)^{2}}{2}\left(\frac{1}{\bar{\sigma}_{22}^{2}}+\frac{1}{\bar{\sigma}_{33}^{2}}-\frac{1}{\bar{\sigma}_{11}^{2}}\right) \\
& \mathrm{L}=\frac{3}{2}\left(\frac{\tau_{0}}{\bar{\sigma}_{23}}\right)^{2} \\
& \mathrm{M}=\frac{3}{2}\left(\frac{\tau_{0}}{\bar{\sigma}_{13}}\right)^{2}
\end{aligned}
$$

where $\bar{\sigma}_{\mathrm{ij}}$ is the yield stress when $\sigma_{\mathrm{ij}}$ is applied as the only nonzero stress component.

Fig. 5 is a multi-scale structural model of non-ideal yarns. The imperfect interface and the fiber waviness were considered in this model. The generalized method of cell (GMC) was adopted to introduce the imperfect interface into the yarn.

\subsubsection{Imperfect bonding interface}

Constitutive equations for the unidirectional fiber-reinforced composites with 
imperfect bonding is given in Reference [15]. The braided yarn can be taken as a unidirectional fiber-reinforced composite. Moreover, the following assumptions are made in the continuum model of yarn:

(1) The continuous fibers are arranged at equal spacing $l_{2}$ periodically in the transverse direction;

(2) Square sections of fibers;

(3) Void free braided yarns.

Fig. 5 exhibits the representative cell of a yarn fragment, having four sub cells. The sub cell $(\beta=\gamma=1)$ represents the carbon fiber and the others represent the resin matrix. The interfaces exist only between the fiber and the resin matrix. The weak interface bonding is submitted at the fiber/matrix interface. The linear jump of displacements across the interface accord with the following relations:

$\mathrm{u}_{\mathrm{n}}=\mathrm{R}_{\mathrm{n}} \sigma_{\mathrm{n}}$

$\mathrm{u}_{\mathrm{t}}=\mathrm{R}_{\mathrm{t}} \sigma_{\mathrm{t}}$

where $\mathrm{u}, \sigma$ are the displacement and traction respectively; and the subscript $\mathrm{n}, \mathrm{t}$ denotes the normal component and the tangential component, respectively. $R_{n}, R_{t}$ are the interface separation factors. If the interface is a perfect bonding, both the value of $R_{n}, R_{t}$ are zero. Based on the GMC method, the constitutive equations of the representative cell of yarn in the elastic range can be derived [15].

\subsubsection{Fiber waviness}

A model of unidirectional composite with uniform waviness is applied to represent the fiber waviness in yarns as shown in Fig. 5. The matrix of yarn with fiber waviness can be derived according to the reference $[16,17]$.

\subsection{Progressive damage model}

The Tsai-Wu strength criterion [18] is used to judge the damage of yarns.

$$
\mathrm{F}_{\mathrm{i}} \sigma_{\mathrm{i}}+\mathrm{F}_{\mathrm{ij}} \sigma_{\mathrm{i}} \sigma_{\mathrm{j}}=1
$$

where $F_{i}$ and $F_{i j}$ are the factors of strength tensors. For the yarn, the expanded form is:

$$
\mathrm{F}_{1} \sigma_{1}+\mathrm{F}_{2}\left(\sigma_{2}+\sigma_{3}\right)+\mathrm{F}_{11} \sigma_{1}^{2}+\mathrm{F}_{22}\left(\sigma_{2}^{2}+\sigma_{3}^{2}\right)+2 \mathrm{~F}_{12}\left(\sigma_{1} \sigma_{2}+\sigma_{3} \sigma_{1}\right)+2 \mathrm{~F}_{23} \sigma_{2} \sigma_{3}+\mathrm{F}_{44} \sigma_{4}^{2}+\mathrm{F}_{55}\left(\sigma_{5}^{2}+\sigma_{6}^{2}\right)=1
$$


The $F_{i}$ and $F_{i j}$ are determined by the tensile, compressive or shear strength of yarn along the $\mathrm{i}-\mathrm{j}$ direction or plane:

$$
\begin{aligned}
& \mathrm{F}_{1}=\frac{1}{\mathrm{X}_{\mathrm{T}}}-\frac{1}{\mathrm{X}_{\mathrm{C}}} ; \mathrm{F}_{2}=\frac{1}{\mathrm{Y}_{\mathrm{T}}}-\frac{1}{\mathrm{Y}_{\mathrm{C}}} ; \mathrm{F}_{11}=\frac{1}{\mathrm{X}_{\mathrm{T}} \mathrm{X}_{\mathrm{C}}} ; \mathrm{F}_{22}=\frac{1}{\mathrm{Y}_{\mathrm{T}} \mathrm{Y}_{\mathrm{C}}} ; \\
& \mathrm{F}_{44}=\frac{1}{\mathrm{~S}_{23}^{2}} ; \mathrm{F}_{55}=\frac{1}{\mathrm{~S}_{31}^{2}} ; \mathrm{F}_{12}=\frac{-\sqrt{\mathrm{F}_{11} \mathrm{~F}_{22}}}{2} ; \mathrm{F}_{23}=\frac{-\mathrm{F}_{22}}{2} ;
\end{aligned}
$$

where T, C denote the tensile or compressive strength respectively; and X, Y stand for the axial or transverse direction respectively; $S_{\mathrm{ij}}$ are pure shear strengths. The axial strengths can be estimated by the modified rule of mixture as reference [19].

The transverse strength of yarn is difficult to determine because of the nonlinear features of matrix near failure and the uniform distribution of stress in matrix. Therefore the following predictions are made based on the reference [19]. If the matrix exhibits brittle failure or the premature interface fails ahead of the yield of matrix, the transverse tensile strength will always be less than the matrix tensile strength. Otherwise, if the matrix is ductile, the transverse tensile strength can be greater than the matrix tensile strength.

In the case of high temperature, the compressive behaviors of the epoxy matrix present obvious ductile failure. The interfacial failure does not dominate in 3D braided composites at high temperatures, especially beyond the glass transition temperature. Therefore, here the transverse strength of yarn is assumed to be greater than the matrix tensile strength. The transverse compressive strength is four times as high as the transverse tensile strength. In addition, the mechanisms of shear failure are similar to the transverse tension failure.

If the left side of the equation (6) exceeds 1, the failure occurs and the mechanical properties of braided yarns will be degraded.

The epoxy matrix is isotropic and strongly temperature-dependent. The failure of matrix may be ductile or brittle depending upon the temperature [20]. Furthermore, the failure theory of matrix should be applied corresponding to the temperature. So the determination of ductile/brittle transition is an essential part of the failure theory. 
A thermomechanical theory of ductile/brittle failure behavior is proposed and the ductile/brittle transition temperature can be predicted by [21]

$$
\begin{aligned}
& \Theta_{\mathrm{D} / \mathrm{B}}=\Theta_{0}+\frac{\mathrm{C}_{\mathrm{m}}}{9 \alpha_{\mathrm{m}} \mathrm{k}_{\mathrm{m}}}\left[1-3 \frac{\mathrm{T}_{\mathrm{m}}}{\mathrm{C}_{\mathrm{m}}}+\sqrt{1-3 \frac{\mathrm{T}_{\mathrm{m}}}{\mathrm{C}_{\mathrm{m}}}+3\left(\frac{\mathrm{T}_{\mathrm{m}}}{\mathrm{C}_{\mathrm{m}}}\right)^{2}}\right], \frac{\mathrm{T}_{\mathrm{m}}}{\mathrm{C}_{\mathrm{m}}} \geq \frac{1}{2} \\
& \Theta_{\mathrm{D} / \mathrm{B}}=\Theta_{0}+\frac{\mathrm{C}_{\mathrm{m}}}{6 \alpha_{\mathrm{m}} \mathrm{k}_{\mathrm{m}}}\left(1-2 \frac{\mathrm{T}_{\mathrm{m}}}{\mathrm{C}_{\mathrm{m}}}\right), \frac{\mathrm{T}_{\mathrm{m}}}{\mathrm{C}_{\mathrm{m}}} \leq \frac{1}{2}
\end{aligned}
$$

$\Theta$ : temperature; $\Theta_{0}$ : the ambient temperature; $a_{m}$ : the linear CTE; $k_{m}$ : the bulk modulus; $\mathrm{C}_{\mathrm{m}}$ : the compressive strength; $\mathrm{T}_{\mathrm{m}}$ : the tensile strength.

For the environmental temperature not exact at the ductile/brittle transition, the ductile versus brittle states of failure are specified by

$\Theta<\Theta_{D / B}$, brittle
$\Theta>\Theta_{D / B}$, ductile

In this article, the ratio of $T_{m} / C_{m}$ of epoxy matrix is $2 / 3$, the ambient temperature is $20^{\circ} \mathrm{C}$, the bulk modulus is $2.44 \mathrm{GPa}$, the compressive strength is $97.6 \mathrm{MPa}$ and the CTE of epoxy is $52.5 \times 10^{-6} /{ }^{\circ} \mathrm{C}$. As a result, the prediction for the ductile/brittle transition temperature of epoxy is $-15.8^{\circ} \mathrm{C}$. Therefore, the ductile failure theory can be applied for the epoxy matrix at high temperatures fields $\left(80^{\circ} \mathrm{C}, 110^{\circ} \mathrm{C}, 140^{\circ} \mathrm{C}\right)$. In addition, the epoxy matrix owns a higher tensile strength than the compressive strength due to the influence of hydrostatic pressure, and a modified version of the von Mises failure criterion in terms of the initial tensile strength and compressive strength is given [22]:

$\left(\frac{1}{T_{m}}-\frac{1}{C_{m}}\right) \sigma_{i i}+\frac{3}{2 C_{m} T_{m}} s_{i j} s_{i j} \leq 1$

where $s_{i j}$ is the deviatoric stress tensor. To ensure computational stability, the maximum value of degradation for matrix was set to 0.9 in this article.

\subsection{Thermoelastic expansion coefficients}

The braided yarn is assumed as a unidirectional composite. Through the Rosen-Hashin's CTE formulas [23], the effective CTE of yarn is derived as 
$\bar{\alpha}_{\mathrm{ij}}^{\mathrm{y}}=\mathrm{V}_{\mathrm{f}} \alpha_{\mathrm{ij}}^{\mathrm{f}}+\left(1-\mathrm{V}_{\mathrm{f}}\right) \alpha_{\mathrm{ij}}^{\mathrm{m}}+\left(\alpha_{\mathrm{kl}}^{\mathrm{f}}-\alpha_{\mathrm{kl}}^{\mathrm{m}}\right) \mathrm{P}_{\mathrm{klmn}}\left(\bar{S}_{\mathrm{mnij}}^{\mathrm{y}}-\mathrm{V}_{\mathrm{f}} S_{\mathrm{mnij}}^{\mathrm{f}}-\left(1-\mathrm{V}_{\mathrm{f}}\right) \mathrm{S}_{\mathrm{mnij}}^{\mathrm{m}}\right)$

$\mathrm{P}_{\text {klmn }}\left(\mathrm{S}_{\mathrm{mnij}}^{\mathrm{f}}-\mathrm{S}_{\mathrm{mnij}}^{\mathrm{m}}\right)=\mathrm{I}_{\mathrm{klij}}$

where $a$ is the CTE; the superscript '-' means the effective component; $f, m$ and $y$ denote the fiber, matrix and yarn, respectively; $S$ is the compliance matrix and the $\mathrm{I}_{\mathrm{klij}}$ is a fourth rank symmetric unit tensor.

\section{Results and discussion}

Hexahedral mesh grids with C3D8R were developed for the regular braided yarns. The tetrahedral meshes with C3D4 were adopted for the mesh discretization of the matrix due to the structural complexity. At room temperature $\left(20^{\circ} \mathrm{C}\right)$ no residual stress in composites was assumed. The temperature distributions of composites were uniform and stable during the tests at high temperature fields. The experimental stress-strain curves are presented in Fig. 6. The mechanical parameters used in this article are listed in Tables 2-5.

\subsection{The stress-strain curves and mechanical properties}

Fig. 7 presents the experimental and numerical calculated stress-strain curves of the longitudinal compression of 3D braided composites with different braided angles at various temperatures. The compression modulus and failure stress of the 3D braided composites are presented in Fig. 8 and Fig. 9 respectively. Through the comparison of the experiment and the FEM results, the FEM model is proved to be effective and the discrepancies are acceptable. It can be concluded from the results that the high temperature and large braided angle decrease the modulus and failure stress of 3D braided composites. From the shape of stress-strain curves, we can see that the 3D braided composites for $48^{\circ}$ braided angle possess the characteristic of ductile failure and own a wide yielding plateau after the yielding point. However, the 3D braided composites for $35^{\circ}$ or $26^{\circ}$ braided angle possess the characteristics of fracture failure and exhibit a decline stage in the stress-strain curves after peak point. Therefore, from the large braided angle to the small braided angle, there is a ductile/brittle failure 
transition angle in the longitudinal compression. Above the transition angle, the longitudinal compression behavior of 3D braided composites will exhibit ductile features. Otherwise, the brittle failure will dominate in the process of longitudinal compression.

In order to find the influence of temperature on the ductile/brittle states of failure, the strain energy density was extracted from the stress-strain curves before the peak point and the plastic part as well as elastic part was distinguished out as shown in Fig. 10. The percentage on the side stands for the ratio of the elastic or plastic part to the total. The proportion of plastic part can be adopted to characterize the ductile/brittle states of failure to some extent. Moreover, greater proportion of plastic part results in more ductile failure. Although both the angles of $35^{\circ}$ and $26^{\circ}$ exhibit a brittle failure, the $35^{\circ}$ presents more ductile compared to the $26^{\circ}$. Although the effect is not obvious as that of the braided angle, the high temperature also makes the failure of 3D braided composites more ductile.

\subsection{Stress distributions at various temperatures}

Fig. 11 shows the stress distributions at the same states of the 3D braided composites for $35^{\circ}$ braided angle at various temperatures. Although, the stress distribution modality is similar at various temperatures, the temperature makes much difference with regard to the level of stress value of matrix. The matrix of composite at high temperature fields bears a low stress with little damage. On the other hand, as compared to resin matrix the stress properties of reinforcement yarns are less affected by change in temperature. Therefore, the way that the high temperature influences the bearing capacity of the composites is mainly through changing the mechanical properties of the matrix.

\subsection{Thermal stress}

\subsubsection{Thermal stress distribution}

Fig. 12 presents the thermal stress distribution along an edge of yarn and the neighboring matrix at various high temperatures, respectively. The thermal stress at 
$140^{\circ} \mathrm{C}$ owns a higher value. The same interval of temperature results in the similar change of thermal strain. However, due to the decrease of the modulus, the increase of thermal stress is not even and the increase of thermal stress at $110^{\circ} \mathrm{C}$ to $140^{\circ} \mathrm{C}$ is less than that at $80^{\circ} \mathrm{C}$ to $110^{\circ} \mathrm{C}$. The increasing range of thermal stress decreases with the increase of temperature. Owing to the edge effect, the value of the thermal stress at the end is a little different from the internal part. The thermal stress of matrix at the internal part was averaged for the convenience of comparison with the matrix failure stress as presented in Fig. 12(b). The thermal stress of matrix with different braided angle is almost the same. However, the high temperature increases the thermal stress of matrix. Conversely, the high temperature decreases the failure stress of matrix. As a result, the ratio of the thermal stress to the failure stress of matrix increases from $8.2 \%$ $\pm 0.3 \%$ at $80^{\circ} \mathrm{C}$ to $19.7 \% \pm 0.9 \%$ at $140^{\circ} \mathrm{C}$. It means, the impact of thermal stress on the failure behaviors of composites may be more apparent at $140^{\circ} \mathrm{C}$ temperature.

\subsubsection{The influence of thermal stress on longitudinal compression}

In order to further investigate how the thermal stress impacts the longitudinal compression behaviors of 3D braided composites, the comparison of FEM results with normal CTE and zero CTE was conducted as shown in Fig. 13. The stress distributions of the epoxy matrix with the normal CTE owns a slightly higher stress than that with zero CTE at the same strain. Conversely, the yarns with zero CTE own a slightly higher stress than that with normal CTE. The non-uniformity of yarn and matrix in CTE leads to the thermal stress at the interface. Moreover, the continuous deformation and the non-uniformity in CTE will result in that one medium endures pressure stress and the other endures pulling stress. The longitudinal stress curves of a node on yarn at the center of composite and the Von Mises stress curves of a node on the adjacent matrix were extracted from the FEM results as presented in Fig. 13(b). The initial thermal stress has different influence on the yarn and the matrix. The matrix with normal CTE yields ahead of that with zero CTE due to the pre-generated thermal stress. However, the thermal stress on the yarn act a role of puller which will offset some stress in the latter compression process. Therefore, the yarn stress with normal CTE will be less than that with zero CTE. This difference between the normal 
CTE and zero CTE will influence the longitudinal compression behaviors around the failure as shown in Fig. 13(c). The failure of composite with zero CTE is slightly ahead of the failure of composite with normal CTE. To some extent, the thermal stress does benefit to the longitudinal compressive properties of 3D braided composites in high temperature fields.

\subsection{Damage analysis}

\subsubsection{Damage evolution versus stress-strain curves with different braided angles}

In order to reveal the different failure mechanisms with different braided angles, the damage status of the yarns and the matrix at three moments around the peak stress point are listed in Fig. 14-16. For $26^{\circ}$ braided angle, the matrix of 3D braided composites has a similar damage status around the peak stress point. However, for $26^{\circ}$ braided angle the surface yarns are more damaged after the peak stress point which results in the sharp drop of the stress after the peak stress point. The phenomenon manifests that the failure mechanism for $26^{\circ}$ braided angle is mainly the fracture of the yarns. For $35^{\circ}$ braided angle, the damage of matrix obviously gets a lot more and forms a zigzag damage zone on profile after the peak stress point. For $35^{\circ}$ braided angle, the damage of yarns gets slightly worse after peak stress point. The damage of the matrix dominates the failure for $35^{\circ}$ braided angle, and this is combined with some fracture of yarns. For $48^{\circ}$ braided angle, the damage of the matrix is similar around the peak stress point and less pronounced as compared to damage at $35^{\circ}$ and $26^{\circ}$. The yarns for $48^{\circ}$ braided angle almost have no obvious damage. The damage of the yarns or the matrix may not be the main failure mechanism of the 3D braided composites for $48^{\circ}$ braided angle but the plastic yielding of the matrix. Therefore, For $48^{\circ}$ braided angle, the failure of $3 \mathrm{D}$ braided composites is more ductile and for $35^{\circ}$ and $26^{\circ}$ braided angle failure is more brittle.

\subsubsection{Damage spatial distribution with different braided angles}

The damage spatial distributions of the $3 \mathrm{D}$ braided composites at $80^{\circ} \mathrm{C}$ are presented by semi transparent figures as shown in Fig. 17. The damage for $26^{\circ}$ braided angle is mainly concentrated at the load end which is also the free end of yarns. The damage for $35^{\circ}$ braided angle is not only at the load end but also around the surface yarn and 
inside the composites. Moreover, a shear damage band was formed that could be seen from the transverse view. However, relatively little damage only appears around the surface yarns for $48^{\circ}$ braided angle.

\subsubsection{Surface yarn deformation on the 3D braided composites}

Six surface yarns at the free end of the 3D braided composites are chosen to investigate the deformation in order to deeply understand the damage morphologies as shown in Fig. 18. The red lines stand for the original distance between the two sides of surface yarns. The blue lines stand for the distance between the two sides of surface yarns under longitudinal compression. To facilitate comparison, the distance between the red lines with the different braided angles are adjusted to the same size as presented in Fig. 18. It is apparently that the distance between the two sides of surface yarns for $26^{\circ}$ and $35^{\circ}$ braided angle gets longer than that for $48^{\circ}$ braided angle after compression. For $48^{\circ}$ braided angle, the distance between two sides of surface yarns is almost unchanged. That means the constraint of yarns at the end of composites with $48^{\circ}$ braided angle is much better and the relative movement of yarns is small. In addition, the larger change of distance signifies the larger dislocation of yarns, and consequently, the matrix between the yarns is apt to form the stress concentration. The stress concentration will lead to the damage of the matrix. That means, the 3D braided composite with a small braided angle is apt to generate damage around the surface yarns at the free end under longitudinal compression.

Fig. 19 presents the damage evolution process of the 3D braided composite for $35^{\circ}$ braided angle from the transverse view. In the beginning, the damage occurs from a side of the composite end. Then, the damage extends along the yarn trajectory direction and the damage also appears around the surface yarns at the same time. Finally, the damage runs through the composite and a zigzag damage zone is formed.

\subsubsection{Experimental photographs of damage morphologies}

Fig. 20 exhibits the optical photographs of the damage morphologies of the 3D braided composites with different braided angles at various temperatures. There is an obvious fracture of yarns for $26^{\circ}$ braided angle and the damage direction is along the braided angle. In addition, the damage of the matrix appears at the end of the 
composites for $26^{\circ}$ and $35^{\circ}$ braided angle. However, the composites for $48^{\circ}$ braided angle have no obvious damage. Apart from the above, the damage of the composites at a higher temperature of $140^{\circ} \mathrm{C}$ becomes slightly less compared with the composites at $80^{\circ} \mathrm{C}$. All of these manifest the consistency of the FEM with the experiments.

\section{Conclusions}

The coupling effect of the braided angle and temperature on the longitudinal compression damage of 3D braided composite was tested and analyzed from quasi-static compression tests and numerical simulation. The ductile/brittle transition temperature is investigated and the ductile failure criterion is adopted for the matrix at the high temperature fields. The ductile/brittle states of failure and the damage modes of the 3D braided composites are strongly dependent on the braided angle. From the large braided angle to the small braided angle, the failure of composites changes from ductile to brittle. The high temperature hardly changes the damage mode but makes the failure of composites more ductile. In addition, the existence of the thermal stress at high temperature fields somewhat improves the longitudinal compressive properties of 3D braided composites. In conclusion, the higher temperature and larger braided angle increase the ductile features of the 3D braided carbon fiber/epoxy composites under longitudinal compression.

\section{Acknowledgements}

The authors acknowledge the financial supports from the Chang Jiang Scholars Program and National Science Foundation of China (Grant Number 11572085 and 51675095). The financial supports from Foundation for the Fok Ying-Tong Education Foundation (Grant No. 141070), Shu-Guang project (Grant No. 14SG31) supported by Shanghai Municipal Education Commission and Shanghai Education Development Foundation, the Fundamental Research Funds for the Central Universities of China and DHU Distinguished Young Professor Program are also gratefully acknowledged. 


\section{References}

1. Li DS, Fang DN, Zhang GB, Hu H. Effect of temperature on bending properties and failure mechanism of three-dimensional braided composite. Materials \& Design, 2012. 41: 167-170.

2. Li DS, Zhao CQ, Ge TQ, Jiang L, Huang CJ, Jiang N. Experimental investigation on the compression properties and failure mechanism of 3D braided composites at room and liquid nitrogen temperature. Composites Part B-Engineering, 2014. 56: 647-659.

3. Pan ZX, Gu BH, Sun BZ. Experimental investigation of high-strain rate properties of 3-D braided composite material in cryogenic field. Composites Part B-Engineering, 2015. 77: 379-390.

4. Pan ZX, Gu BH, Sun BZ. Longitudinal compressive behaviour of 3D braided composite under various temperatures and strain rates. Applied Physics a-Materials Science \& Processing, 2015. 118(4): 1315-1337.

5. Zhang W, Pan ZX, Gideon RK, Gu BH, Sun BZ. Effects of temperature and strain rate on impact compression behaviors of three-dimensional carbon fiber/epoxy braided composites. Journal of Composite Materials, 2015. 49(7): 771-782.

6. Fang GD, Liang J, Lu Q, Wang BL, Wang Y. Investigation on the compressive properties of the three dimensional four-directional braided composites. Composite Structures, 2011. 93(2): 392-405.

7. Li DS, Fang DN, Jiang N, Yao XF. Finite element modeling of mechanical properties of 3D five-directional rectangular braided composites. Composites Part B-Engineering, 2011. 42(6): 1373-1385.

8. Shokrieh MM, Mazloomi MS. A new analytical model for calculation of stiffness of three-dimensional four-directional braided composites. Composite Structures, 2012. 94(3): 1005-1015.

9. Zhang $\mathrm{C}, \mathrm{Xu} \mathrm{XW}$. Finite element analysis of 3D braided composites based on three unit-cells models. Composite Structures, 2013. 98: 130-142.

10. $\mathrm{Xu} \mathrm{L}$, Jin $\mathrm{CZ}$, Ha SK. Ultimate strength prediction of braided textile composites using a multi-scale approach. Journal of Composite Materials, 2015. 49(4): 477-494.

11. $\mathrm{Xu} \mathrm{K,} \mathrm{Qian} \mathrm{XM.} \mathrm{Analytical} \mathrm{prediction} \mathrm{of} \mathrm{the} \mathrm{elastic} \mathrm{properties} \mathrm{of} \mathrm{3D} \mathrm{braided}$ composites based on a new multiunit cell model with consideration of yarn distortion. Mechanics of Materials, 2016. 92: 139-154.

12. Lubliner J. Plasticity theory. Dover, 1990.

13. $\mathrm{R} \mathrm{H}$. A theory of the yielding and plastic flow of anisotropic metals. Proceedings of the Royal Society A, 1948. 193(1033): 281-297.

14. Sun CT, Chen JL. A simple flow rule for characterizing nonlinear behavior of fiber composites. Journal of Composite Materials, 1989. 23(10): 1009-1020.

15. Aboudi J. Constitutive equations for elastoplastic composites with imperfect bonding. International Journal of Plasticity, 1988. 4(2): 103-125. 
16. Hsiao HM, Daniel IM. Effect of fiber waviness on stiffness and strength reduction of unidirectional composites under compressive loading. Composites Science and Technology, 1996. 56(5): 581-593.

17. Hsiao HM, Daniel IM. Elastic properties of composites with fiber waviness. Composites Part a-Applied Science and Manufacturing, 1996. 27(10): 931-941.

18. Tsai SW, Wu EM. A general theory of strength for anisotropic materials. Journal of Composite Materials, 1971. 5: 58-80.

19. Tsai SW, Hahn HT. Introduction to Composite Materials. 1980.

20. Kody RS, Lesser AJ. Deformation and yield of epoxy networks in constrained states of stress. Journal of Materials Science, 1997. 32(21): 5637-5643.

21. Christensen RM. Evaluation of Ductile/Brittle Failure Theory and Derivation of the Ductile/Brittle Transition Temperature. Journal of Applied Mechanics-Transactions of the Asme, 2016. 83(2).

22. Raghava R, Caddell RM. The macroscopic yield behaviour of polymers. Journal of Materials Science, 1973. 8: 225-232.

23. Rosen BW, Hashin Z. Effective thermal expansion coefficients and specific heats of composite materials. International Journal of Engineering Science, 1970. 8(2): 157-173. 


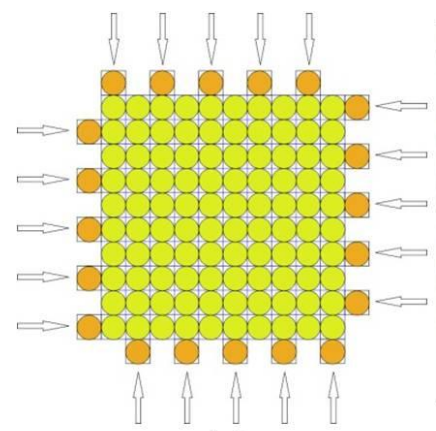

(a)

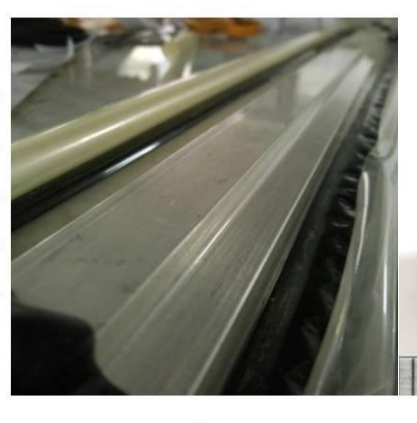

(b)

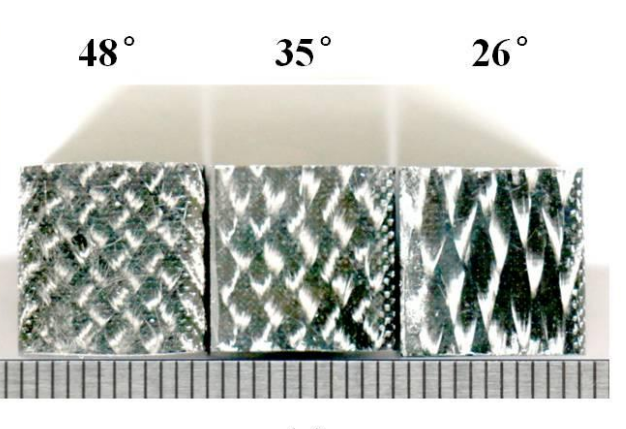

(c)

Fig. 1 Sample preparation (a) 4-step $1 \times 1$ braided method; (b) curing by VARTM; (c) samples with different braided angles

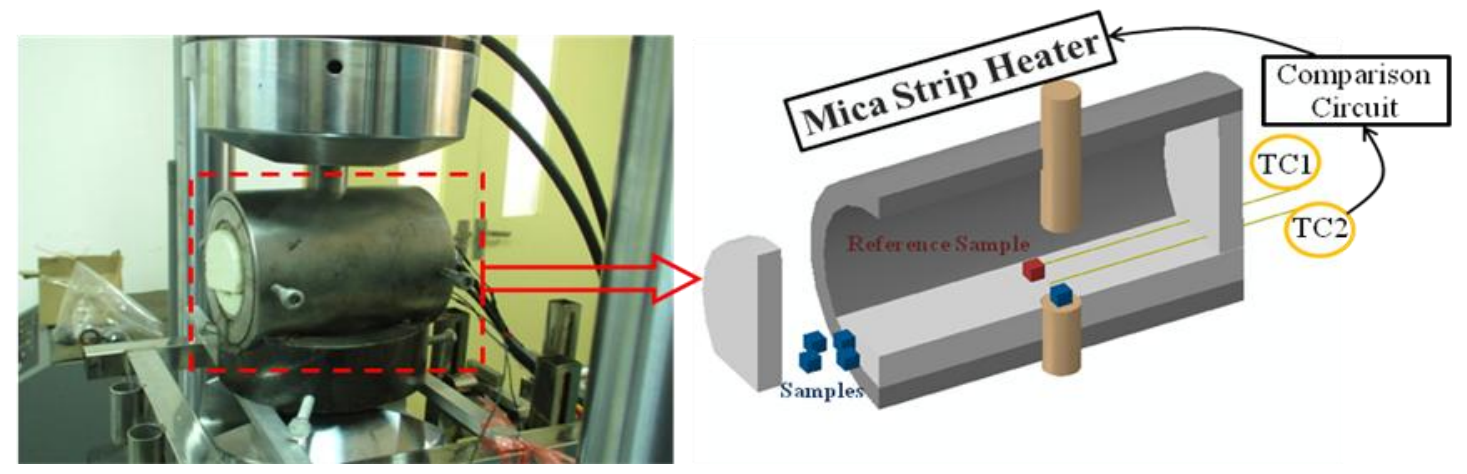

Fig. 2 Experimental setup and the schematic diagram of high-temperature chamber 


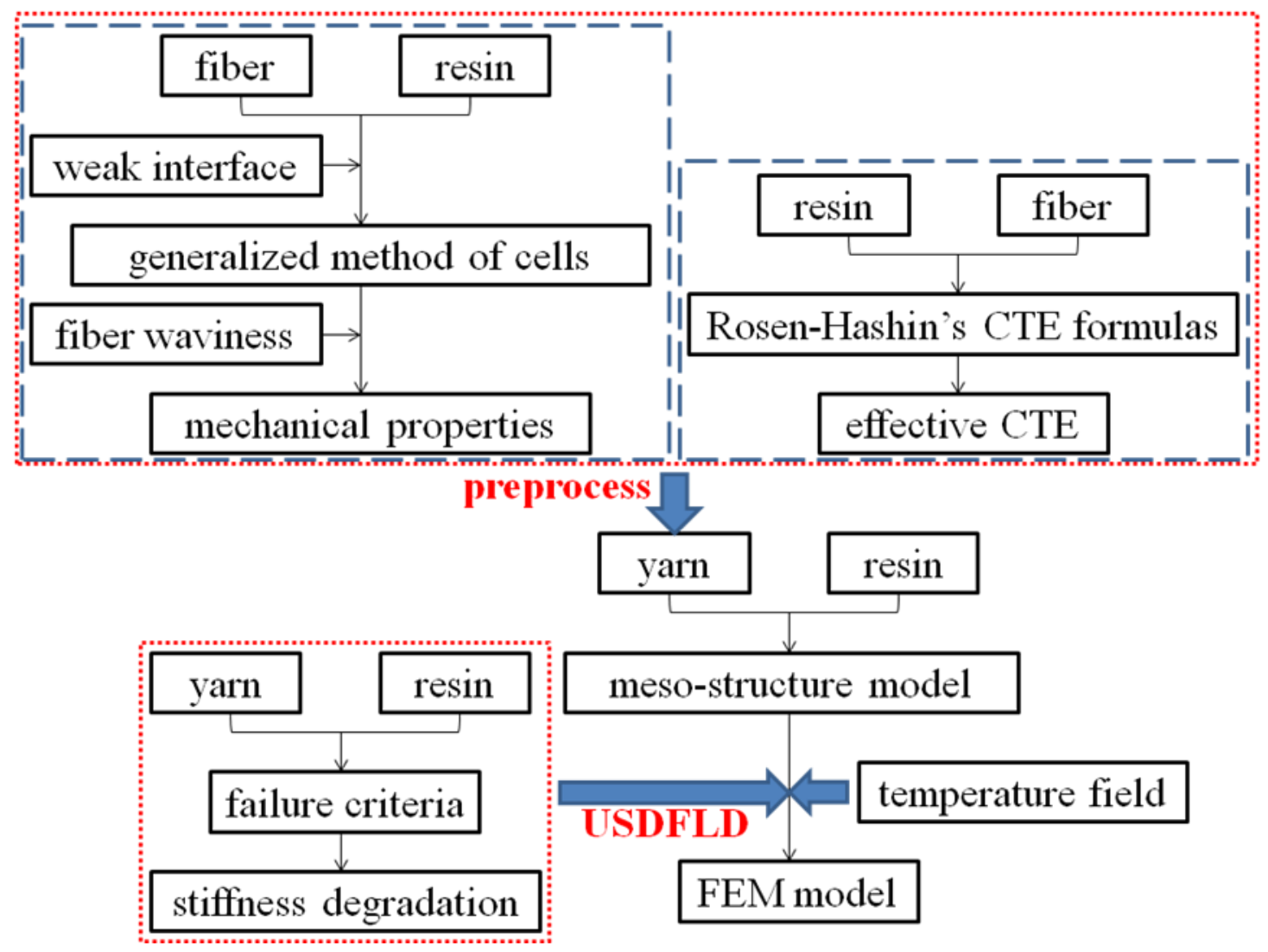

Fig. 3 Framework of FEM model for 3D braided composites

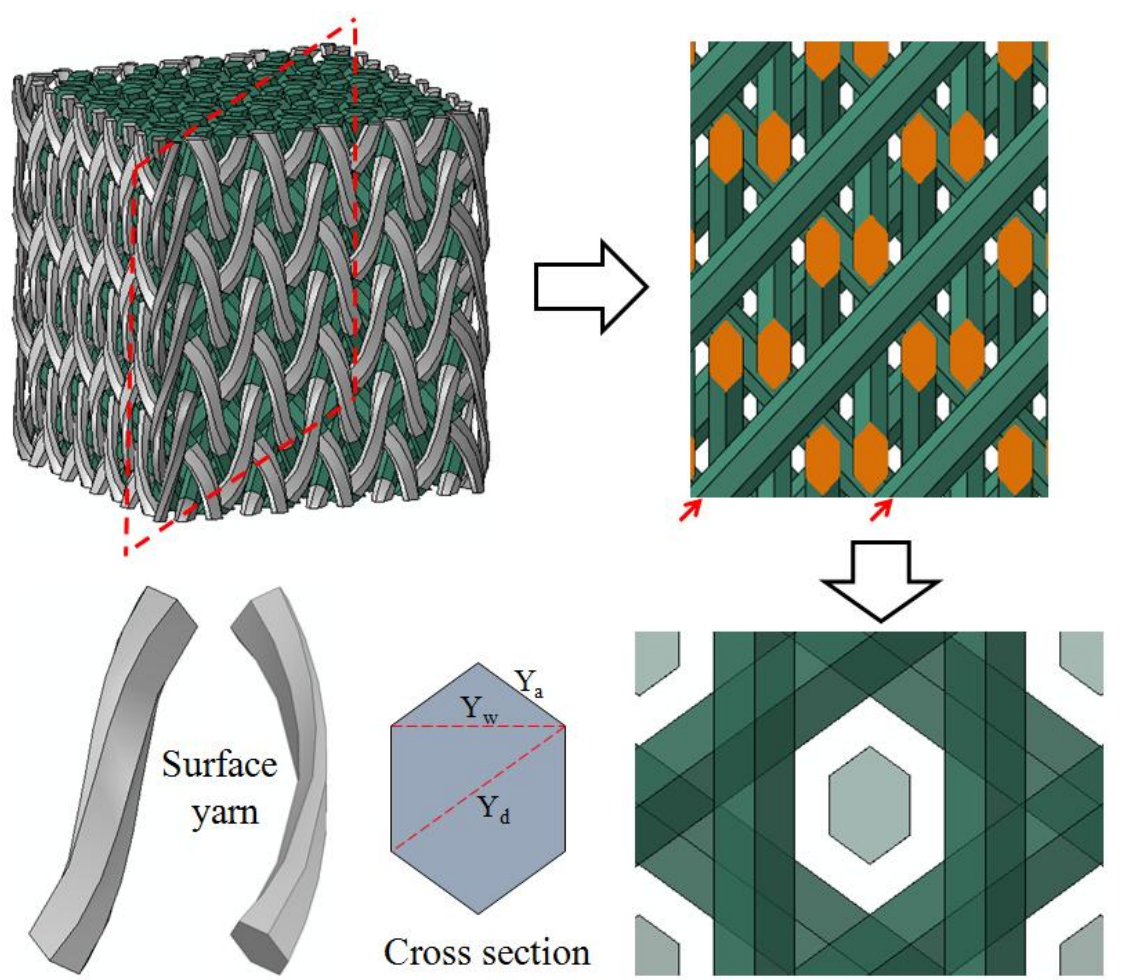

Fig. 4 Geometric model 


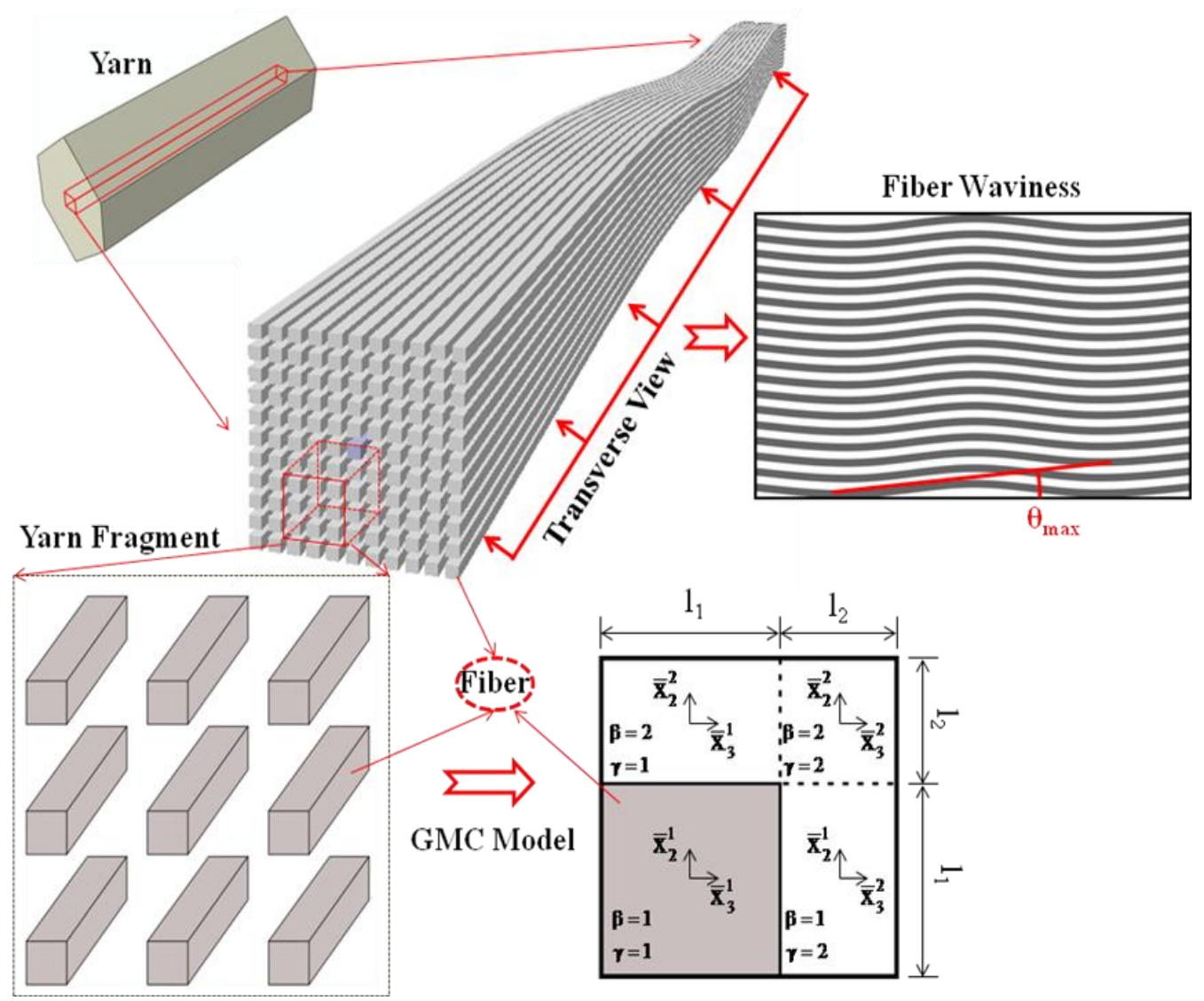

Fig. 5 Multi-scale structures of yarns 
(a)

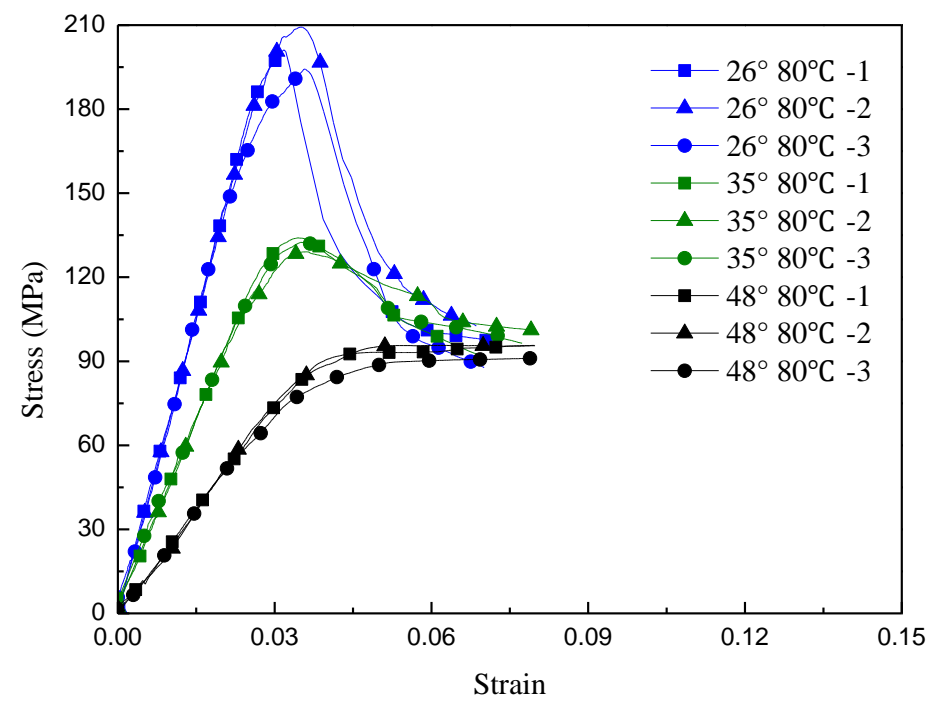

(b)

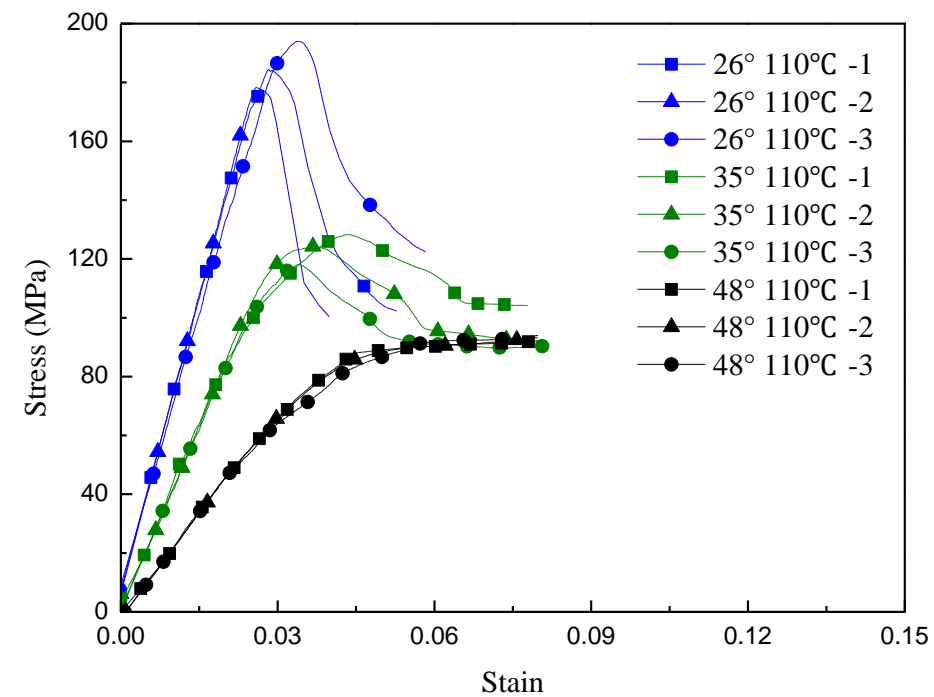

(c)

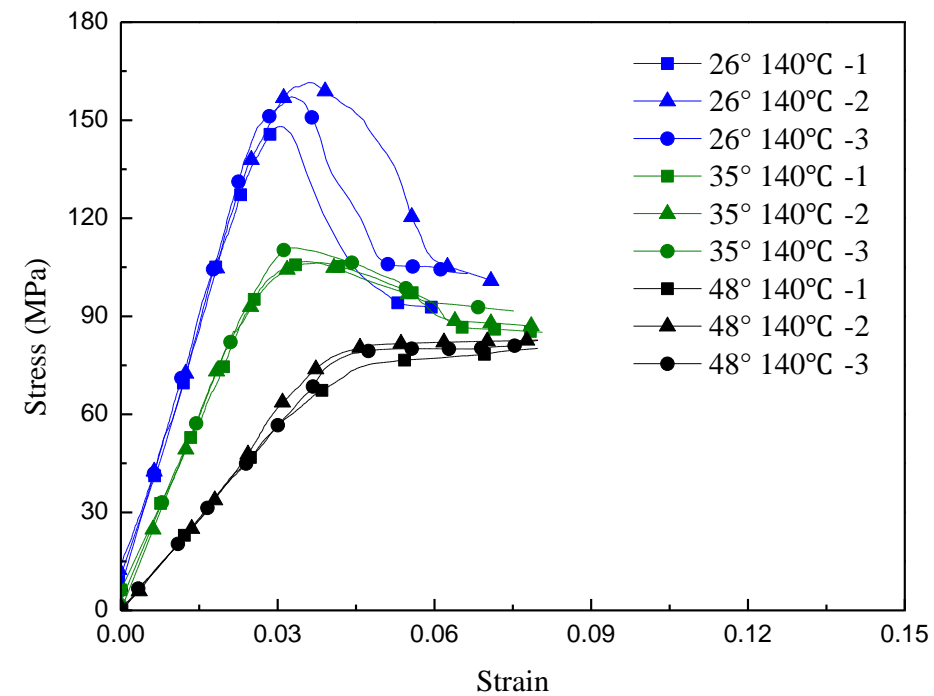

Fig. 6 Experimental stress-strain curves (a) $80^{\circ} \mathrm{C}$; (b) $110^{\circ} \mathrm{C}$; (c) $140^{\circ} \mathrm{C}$ 
(a)

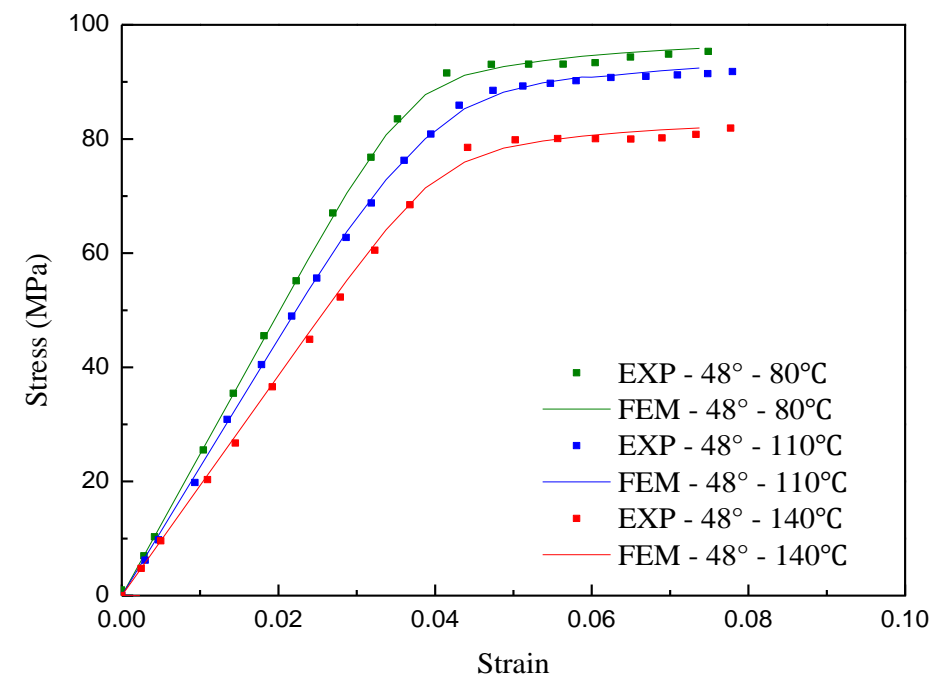

(b)

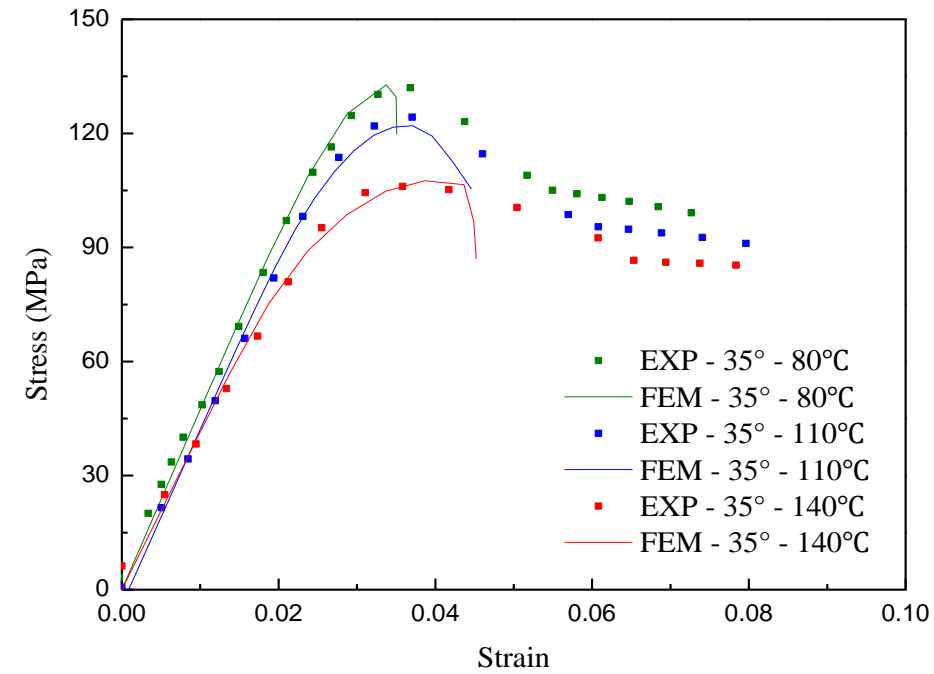

(c)

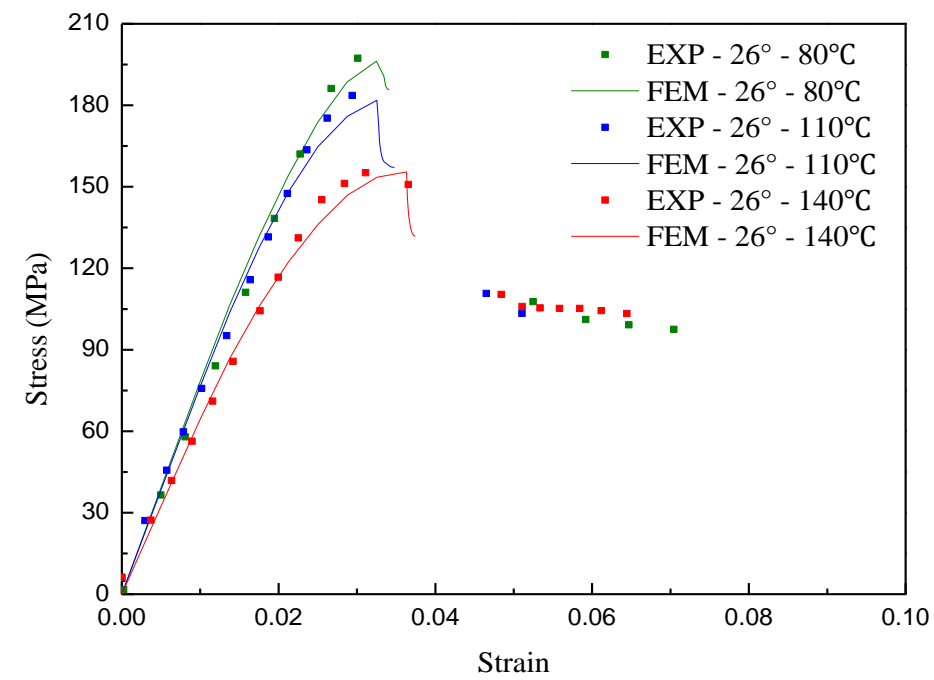

Fig. 7 Comparison between experimental and FEM (a) $48^{\circ}$; (b) $35^{\circ}$; (c) $26^{\circ}$ 


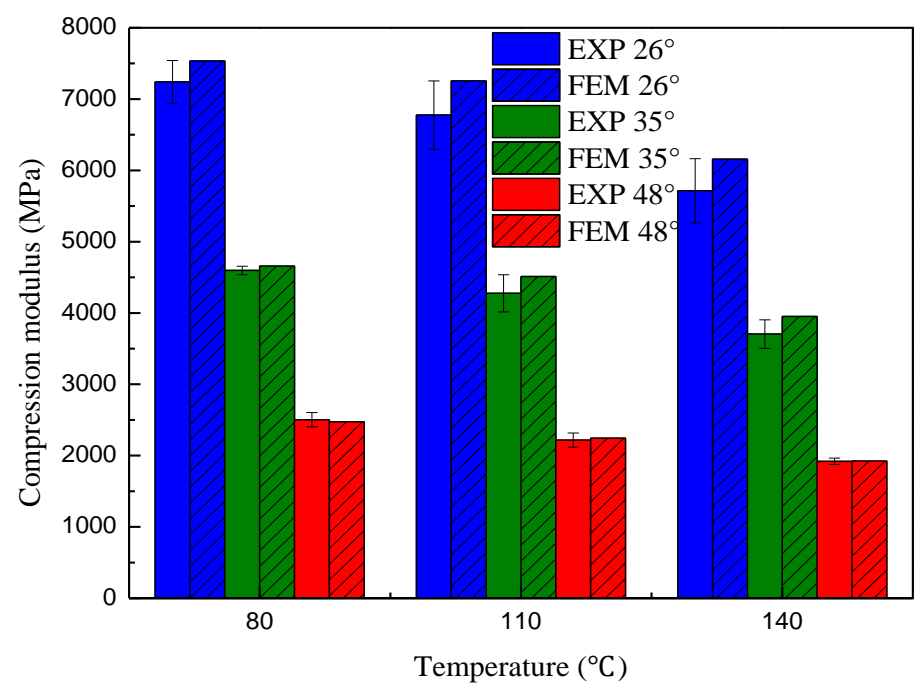

Fig. 8 Compression modulus of 3D braided composites at various temperatures

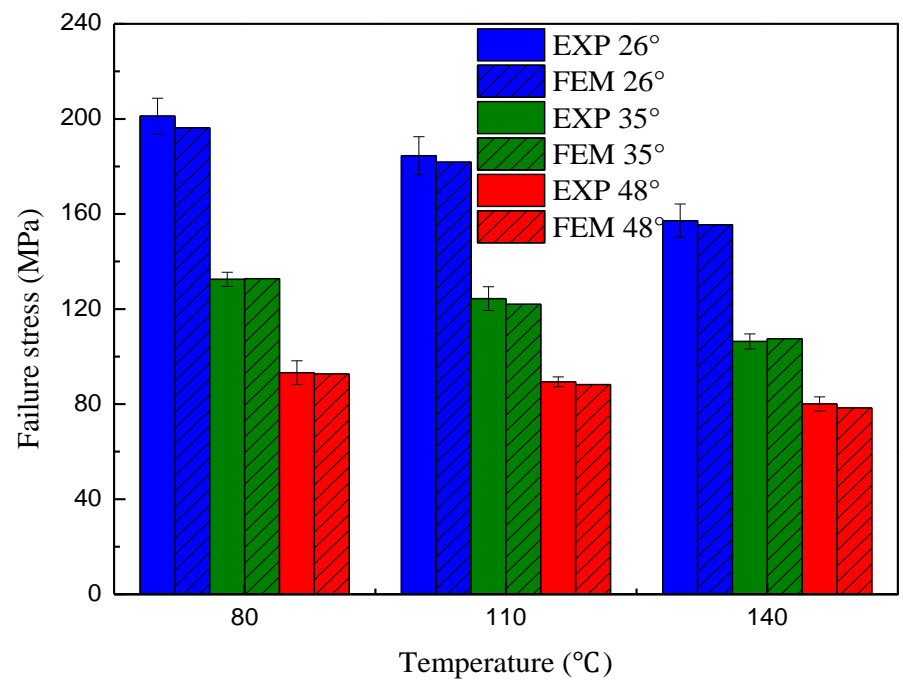

Fig. 9 Failure stress of 3D braided composites at various temperatures 


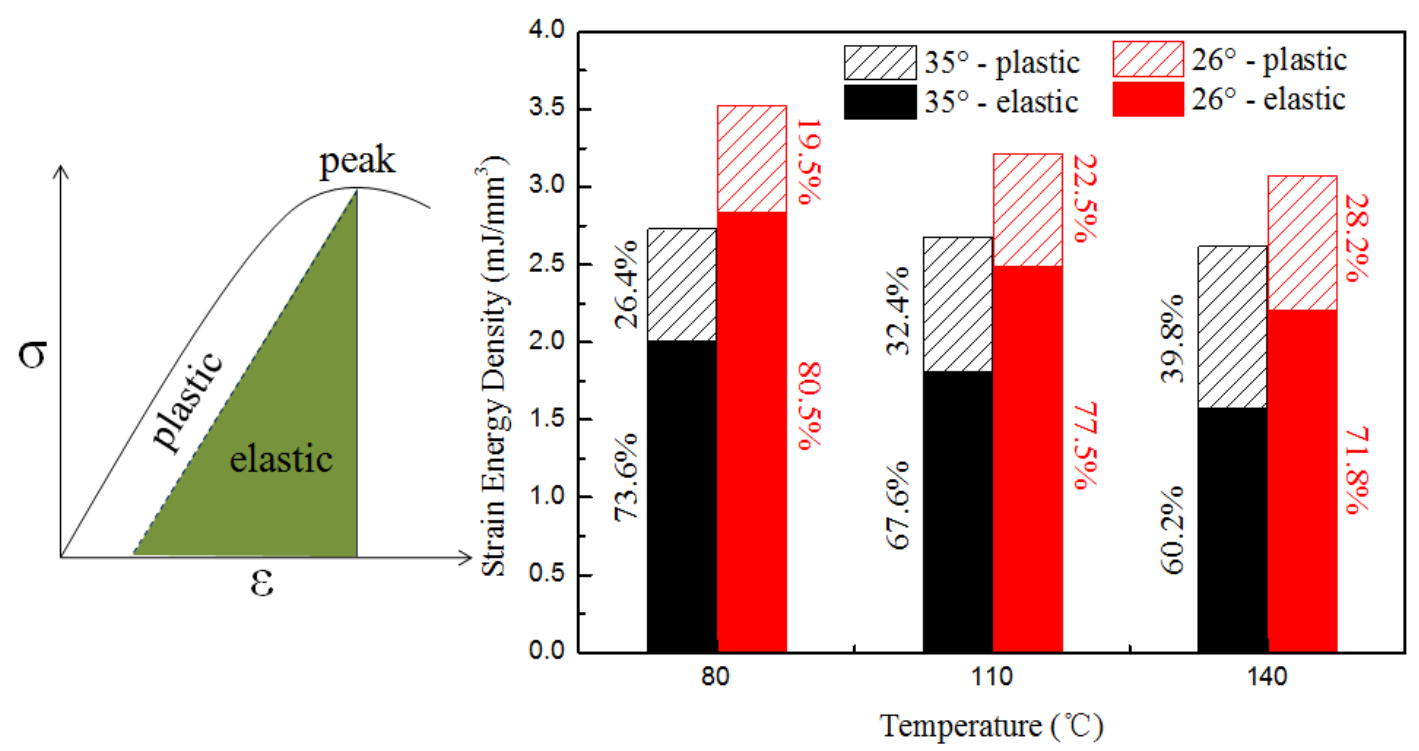

Fig. 10 Strain energy density at various temperatures

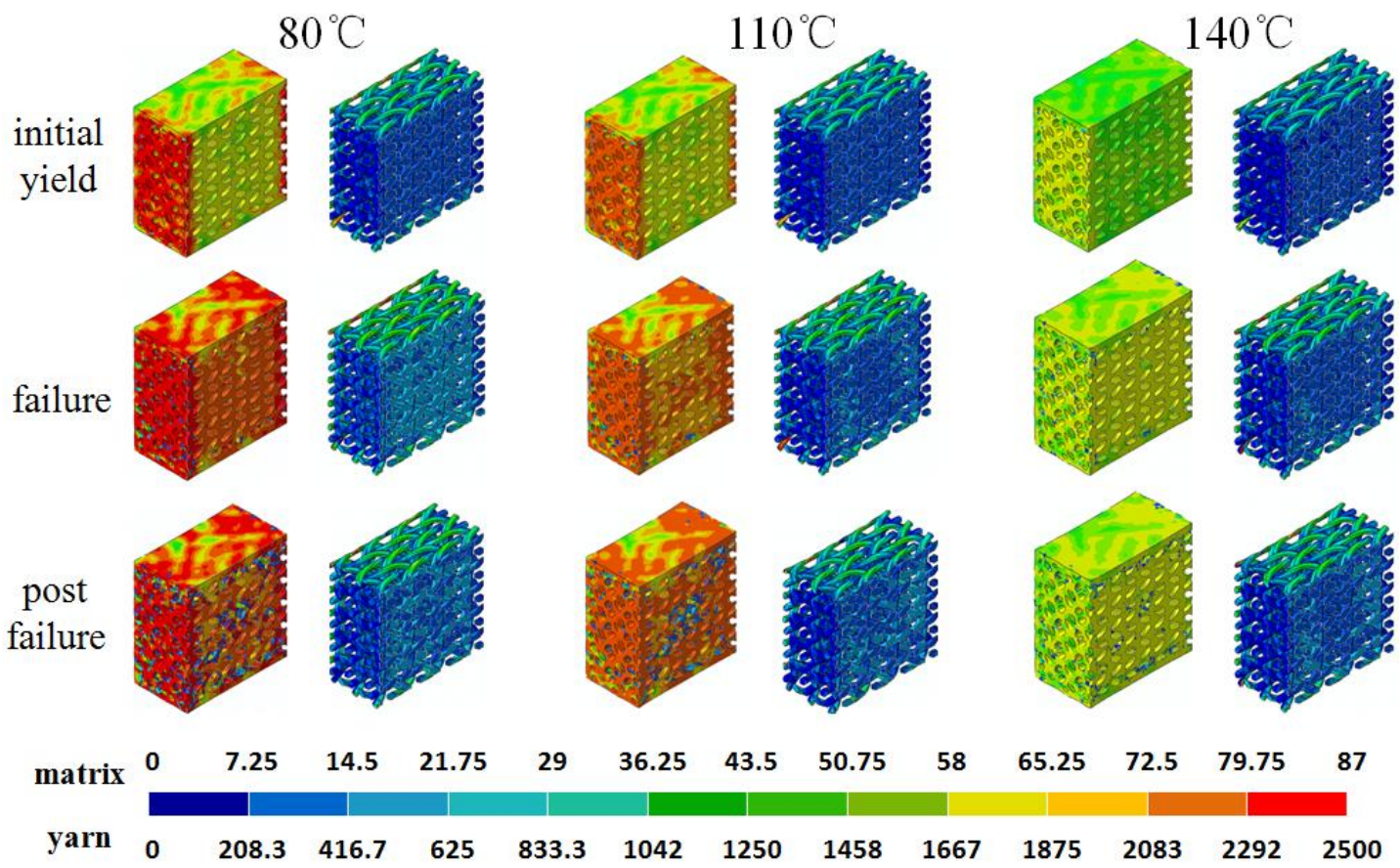

Fig. 11 Stress distributions of $3 \mathrm{D}$ braided composites for $35^{\circ}$ braided angle at various temperatures 


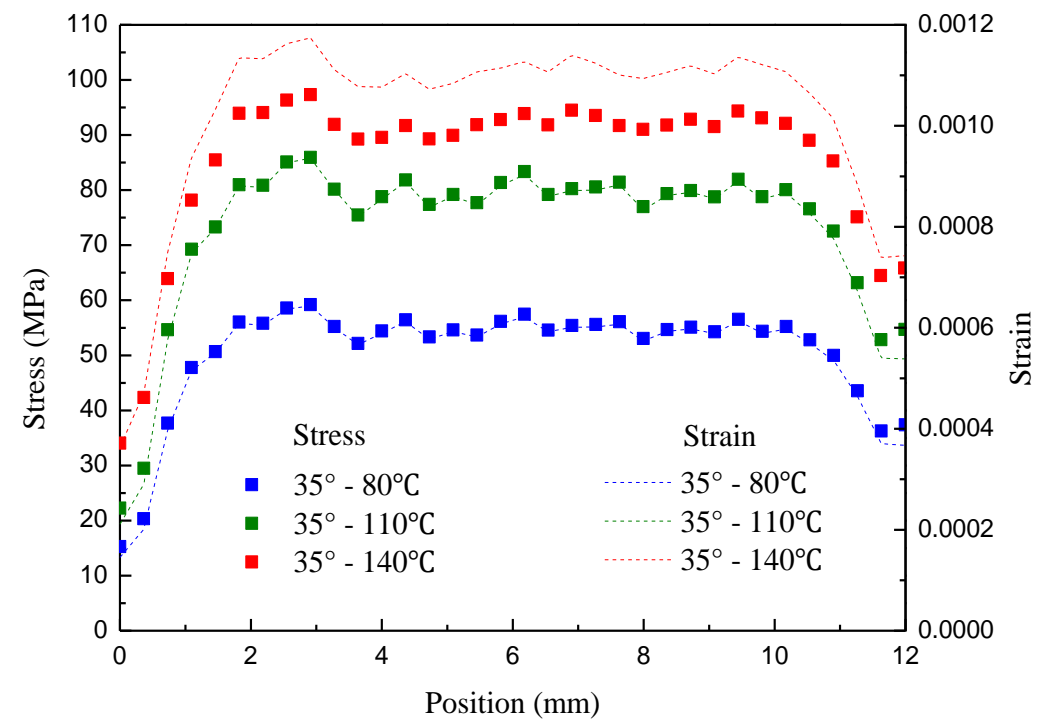

(a)
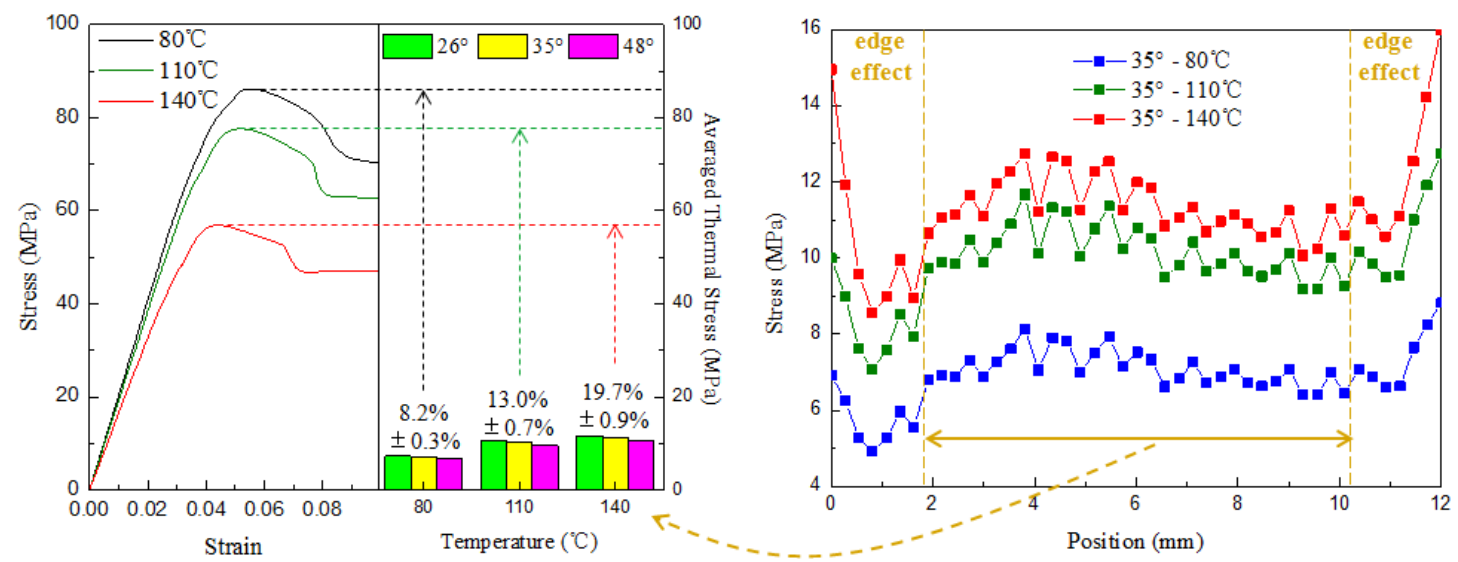

(b)

Fig. 12 Thermal stress distribution along yarn by axial location at various temperatures (a) yarn; (b) matrix 


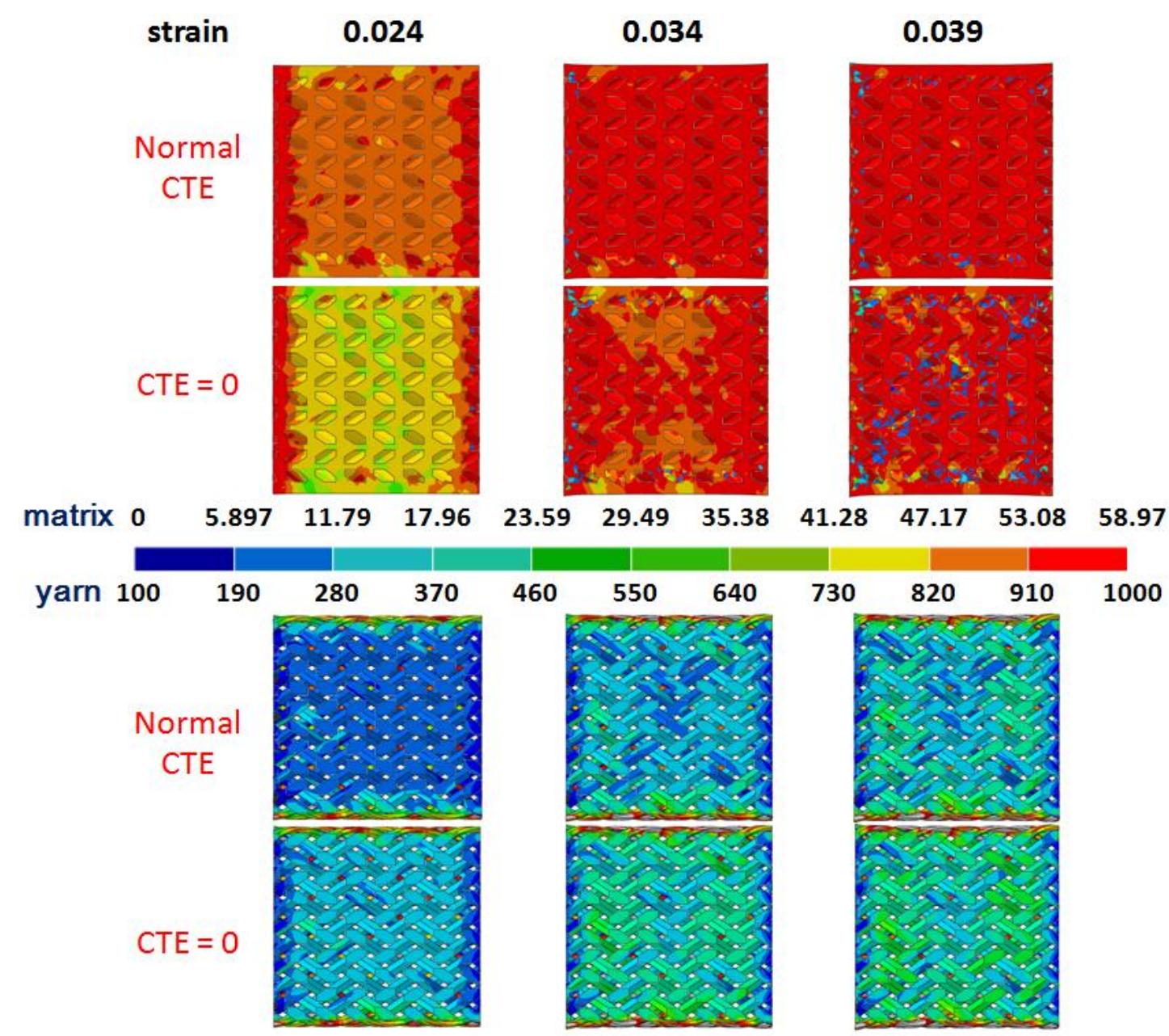

(a)
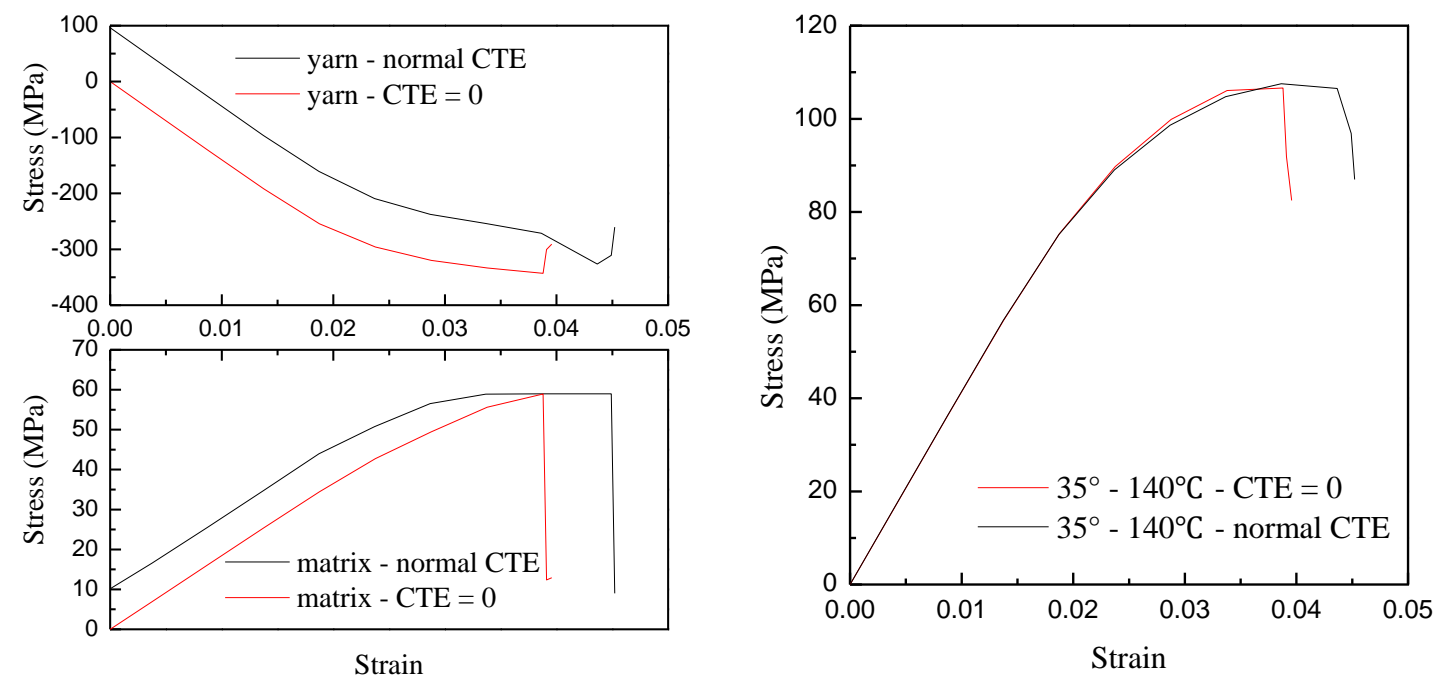

(b)

(c)

Fig. 13 Comparison of FEM results with normal CTE and zero CTE for $35^{\circ}$ braided angle at $140^{\circ} \mathrm{C}$ (a) stress distributions; (b) stress evolution curves of the nodes on the yarn and the adjacent matrix at the center part of composite; (c) stress-strain curves of composites 


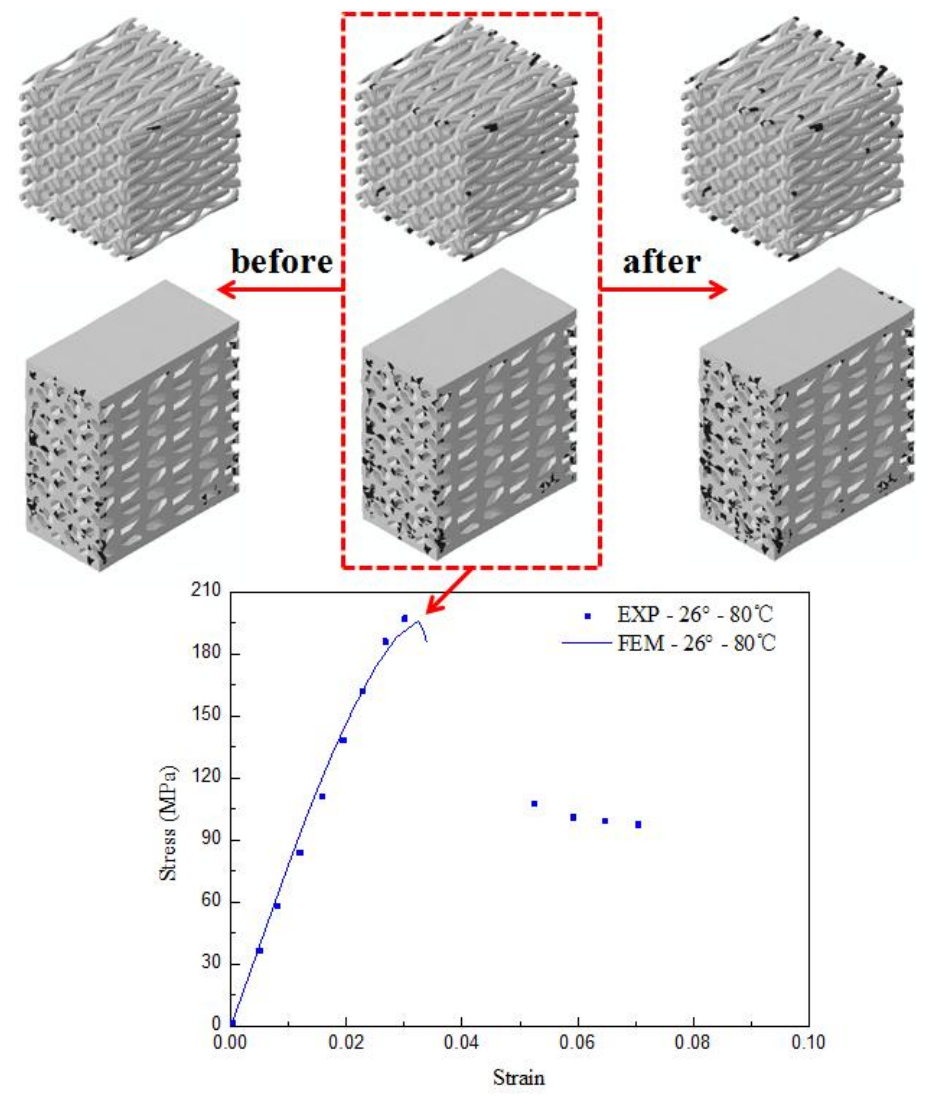

Fig. 14 Damage evolution of the 3D braided composite for $26^{\circ}$ braided angle at $80^{\circ} \mathrm{C}$

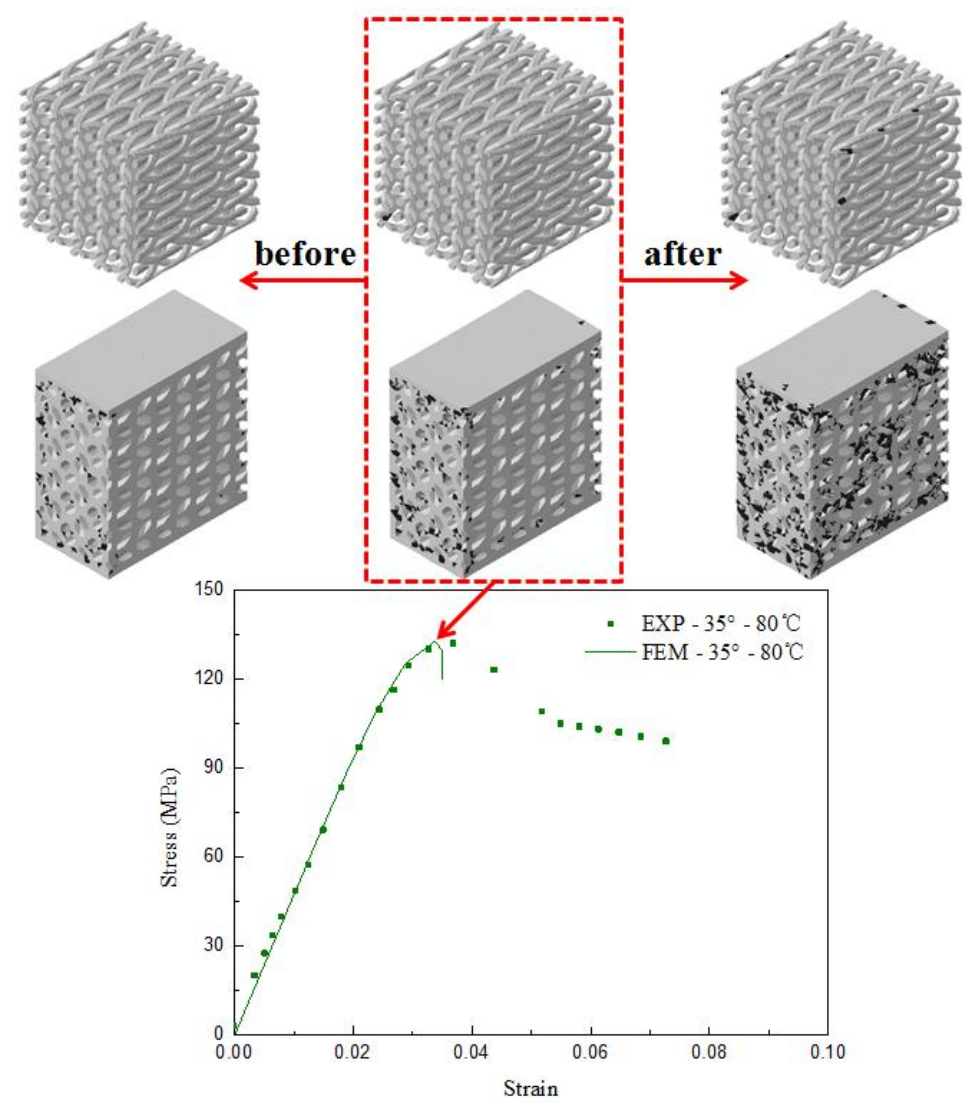

Fig. 15 Damage evolution of the $3 \mathrm{D}$ braided composite for $35^{\circ}$ braided angle at $80^{\circ} \mathrm{C}$ 


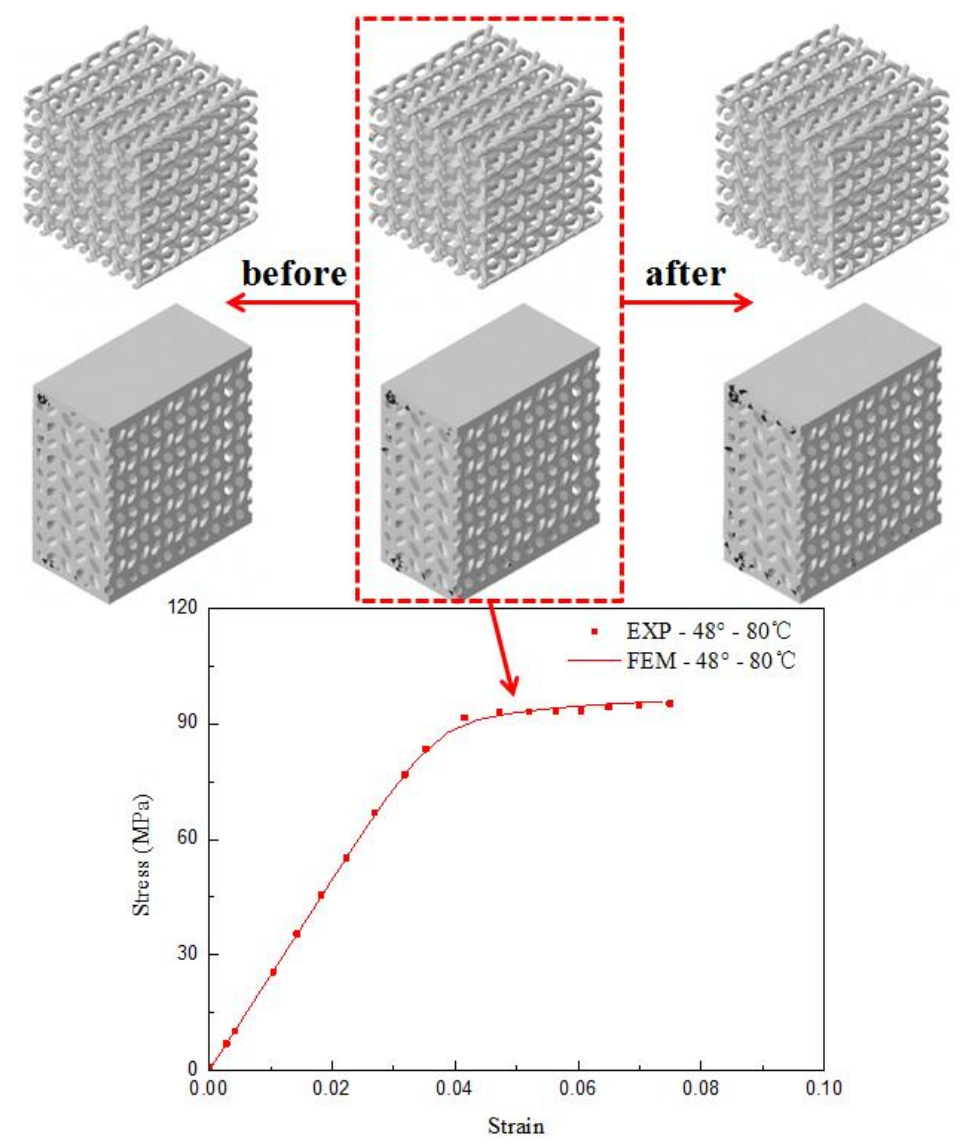

Fig. 16 Damage evolution of the 3D braided composite for $48^{\circ}$ braided angle at $80^{\circ} \mathrm{C}$

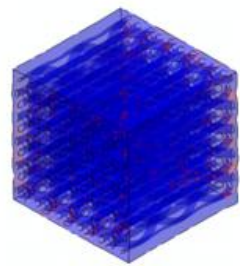

$26^{\circ}-80^{\circ} \mathrm{C}$
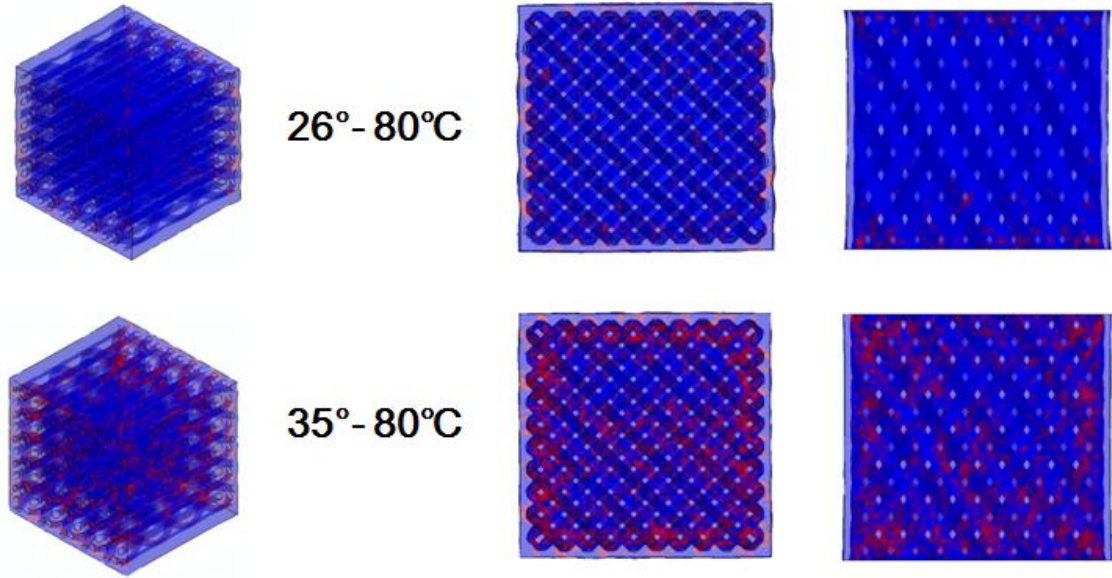

$35^{\circ}-80^{\circ} \mathrm{C}$
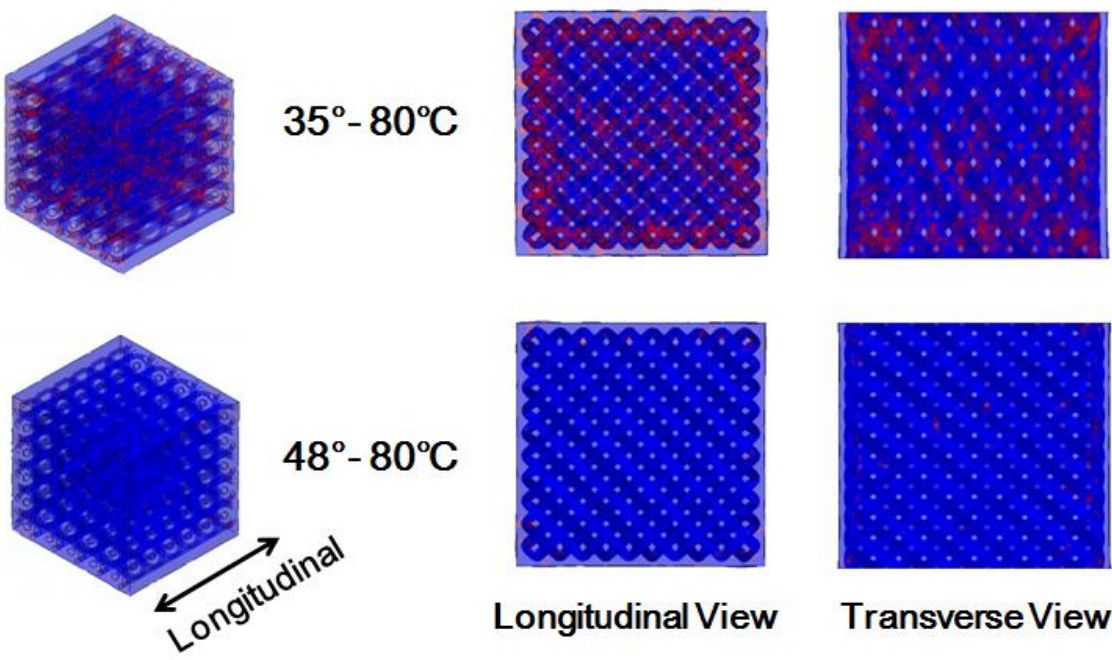

Longitudinal View Transverse View

Fig. 17 Damage spatial distribution of the 3D braided composites with different braided angles at $80^{\circ} \mathrm{C}$ 

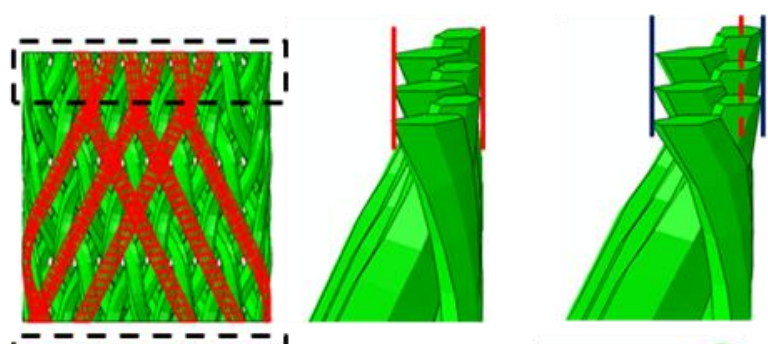

$26^{\circ}$
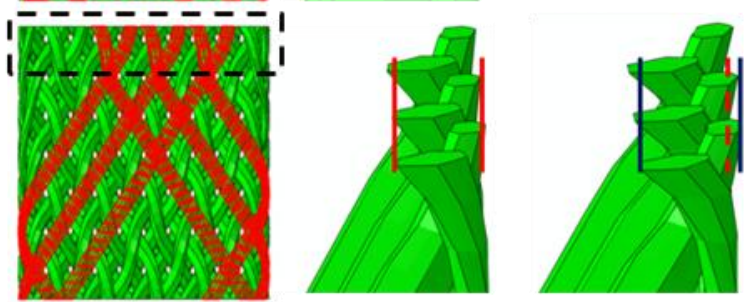

$35^{\circ}$
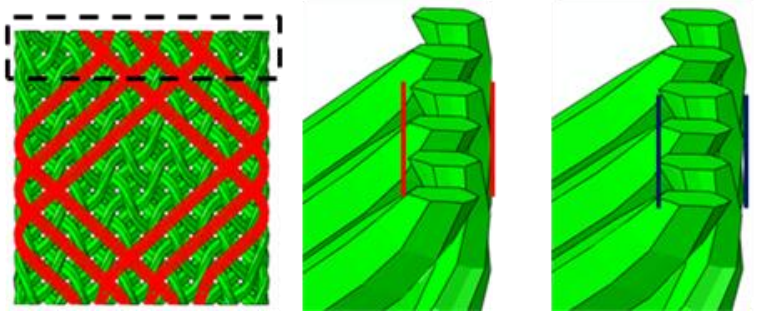

$48^{\circ}$

Fig. 18 The surface yarn deformation on the edge of the 3D braided composites with different braided angles at $80^{\circ} \mathrm{C}$
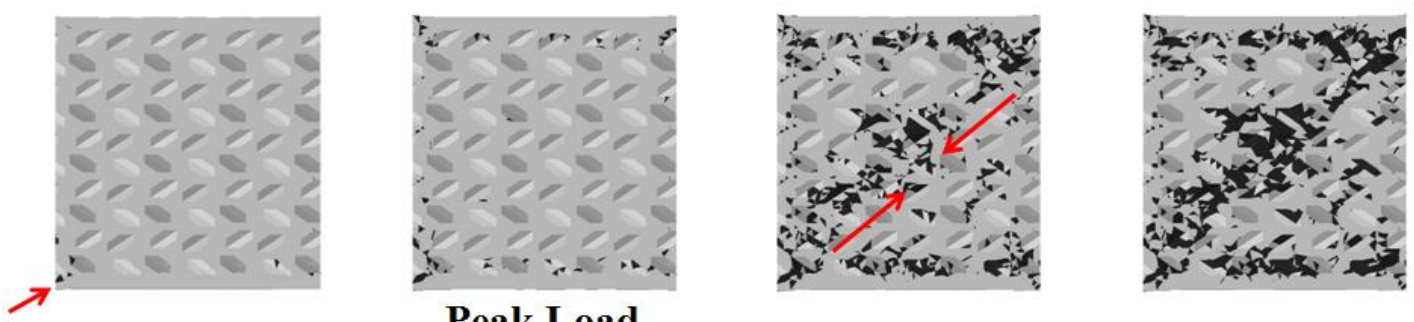

\section{Peak Load}

Fig. 19 Evolution of the matrix damage and the stress distribution of yarns for $35^{\circ}$ braided angle at $80^{\circ} \mathrm{C}$ 


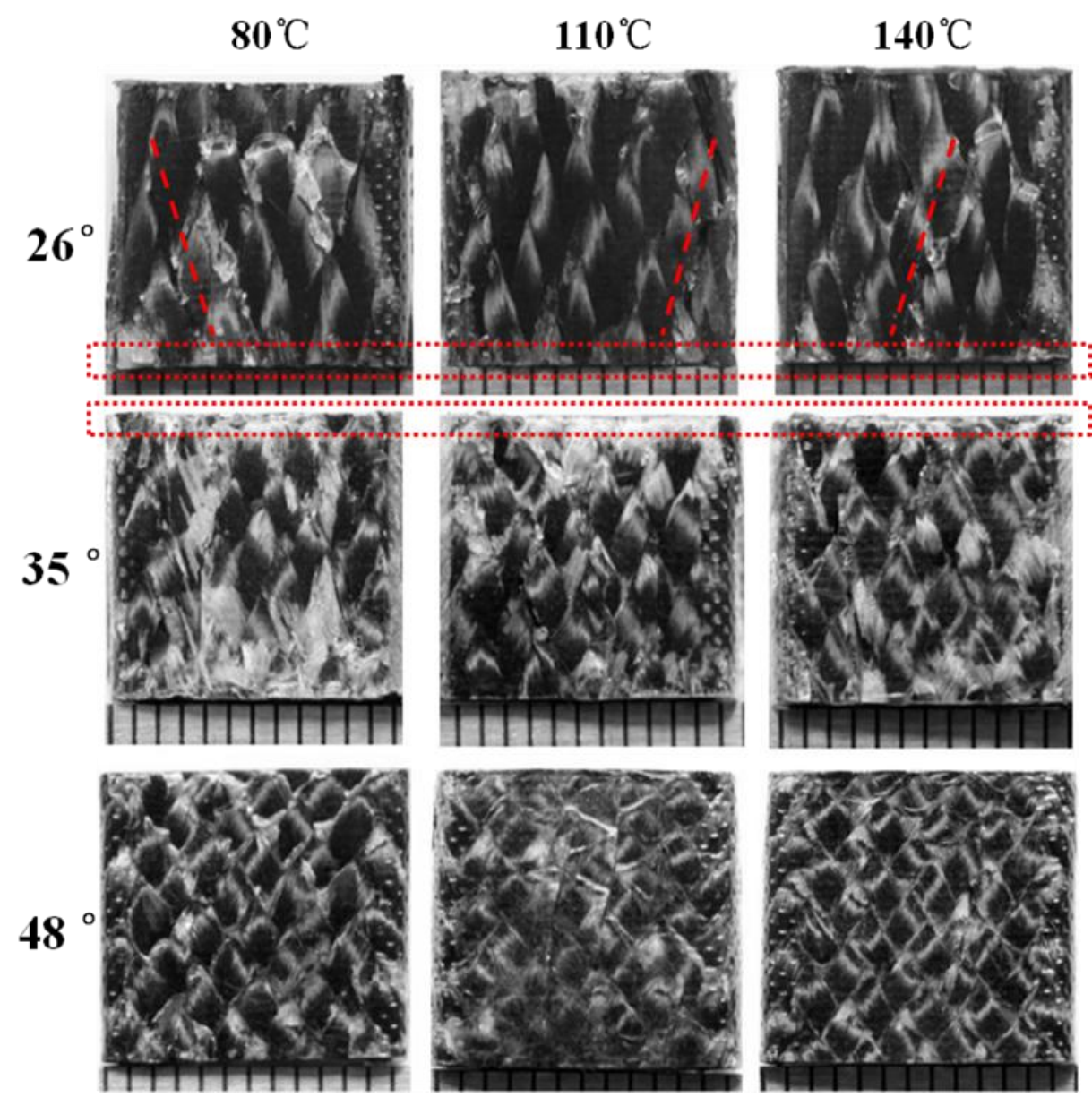

Fig. 20 The damage morphologies of the 3D braided composites with different braided angles at various temperatures 
Table 1 Coupon specifications

\begin{tabular}{ccccc}
\hline $\begin{array}{c}\text { braided } \\
\text { angle }\left({ }^{\circ}\right)\end{array}$ & $\begin{array}{c}\text { pitch length } \\
(\mathrm{mm})\end{array}$ & $\begin{array}{c}\text { specimen size } \\
(\mathrm{mm})\end{array}$ & $\begin{array}{c}\text { fiber volume } \\
\text { fraction }(\%)\end{array}$ & temperature $\left({ }^{\circ} \mathrm{C}\right)$ \\
\hline 48 & 2.2 & & & \\
35 & 3.4 & $12 \times 12 \times 12$ & $32 \pm 2$ & $80,110,140$ \\
26 & 4.8 & & & \\
\hline
\end{tabular}

Table 2 Mechanical parameters of carbon fiber

\begin{tabular}{cccccccc}
\hline $\begin{array}{c}\mathrm{E}_{11} \\
(\mathrm{GPa})\end{array}$ & $\begin{array}{c}\mathrm{E}_{22} \\
(\mathrm{GPa})\end{array}$ & $v_{12}$ & $v_{23}$ & $\begin{array}{c}\mathrm{G}_{12} \\
(\mathrm{GPa})\end{array}$ & $\begin{array}{c}\mathrm{a}_{11} \\
\left(10^{-6} /{ }^{\circ} \mathrm{C}\right)\end{array}$ & $\begin{array}{c}\mathrm{a}_{22} \\
\left(10^{-6} /{ }^{\circ} \mathrm{C}\right)\end{array}$ & $\begin{array}{c}\mathrm{XT} \\
(\mathrm{MPa})\end{array}$ \\
\hline 230 & 11.8 & 0.2 & 0.25 & 9 & -0.54 & 10.1 & 4900 \\
\hline
\end{tabular}

Table 3 Mechanical parameters of epoxy resin

\begin{tabular}{cccccc}
\hline $\mathrm{E}_{\mathrm{m}}(\mathrm{MPa})$ & $v_{\mathrm{m}}$ & $\mathrm{a}_{\mathrm{m}}\left(10^{-6} /{ }^{\circ} \mathrm{C}\right)$ & $\mathrm{T}_{\mathrm{m}}(\mathrm{MPa})$ & $\mathrm{C}_{\mathrm{m}}(\mathrm{MPa})$ & temperature $\left({ }^{\circ} \mathrm{C}\right)$ \\
\hline 2192 & 0.35 & 52.5 & 65 & 98 & 20 \\
2029 & 0.35 & 52.5 & 58 & 87 & 80 \\
1927 & 0.35 & 52.5 & 52 & 78 & 110 \\
1616 & 0.35 & 52.5 & 39 & 58 & 140 \\
\hline
\end{tabular}

Table 4 Equivalent engineering constants of yarn

\begin{tabular}{ccccccc}
\hline $\mathrm{E}_{11}(\mathrm{MPa})$ & $\mathrm{E}_{22}(\mathrm{MPa})$ & $v_{12}$ & $v_{23}$ & $\mathrm{G}_{12}(\mathrm{MPa})$ & $\mathrm{G}_{23}(\mathrm{MPa})$ & temperature $\left({ }^{\circ} \mathrm{C}\right)$ \\
\hline 89485 & 1234 & 0.2722 & 0.2816 & 612 & 482 & 80 \\
89245 & 1229 & 0.2723 & 0.2814 & 608 & 480 & 110 \\
80211 & 1149 & 0.2773 & 0.2804 & 560 & 448 & 140 \\
\hline
\end{tabular}


Table 5 Equivalent CTE of yarn

\begin{tabular}{ccc}
\hline longitudinal CTE $\left(10^{-7}\right)$ & transverse CTE $\left(10^{-5}\right)$ & temperature $\left({ }^{\circ} \mathrm{C}\right)$ \\
\hline-3.75 & 1.53 & 80 \\
-3.80 & 1.53 & 110 \\
-4.10 & 1.52 & 140 \\
\hline
\end{tabular}

